\title{
THE ROLE OF THE URBAN MANAGEMENT \\ IN SOLVING THE URBAN PROBLEMS (ASSIUT CITY AS A CASE STUDY)
}
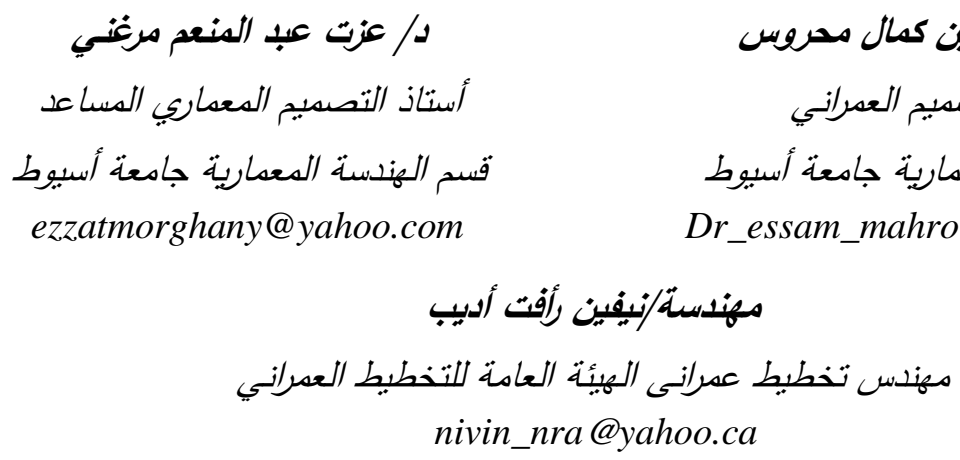

(Received February 28, 2009 Accepted May 2, 2009)

The urban land management process has become one of the most important pillars for the urban sustainable development, so a lot of researches have concerned with studying its components, and most important impediments which affect the efficiency of the outputs of that process.

Some of the cities in the Arab Republic of Egypt-including Assiut Citysuffer from urban land management shortage problems, which cause a lot of physical problems impeding the urban sustainable development in those cities, and so those problems were the focus of many planning studies.

The paper aims to study the components of the urban land management, and the potentials to apply them in Assiut City, in order to alleviate the urban land management shortage problems.

The paper begins with browsing of the physical problems in Assiut City caused from the urban land management shortage, then the concept and the components of the urban land management process, and so the city need for an urban land management system, and the potentials to apply its components in that city, and so reaching to the paper recommendations, which can help in supporting those potentials, to go forward towards the urban sustainable development in Assiut City. 
دور إدارة الأراضي الحضرية في حل المشكلات العمرانية

(دراسة حالة مدينة أسيوط)

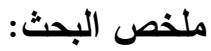

أصبحت عملية إدارة الأراضي الحضرية من أهم ركائز التتمية الحضرية المستدامة، لذلك فقد تم الاهتمام

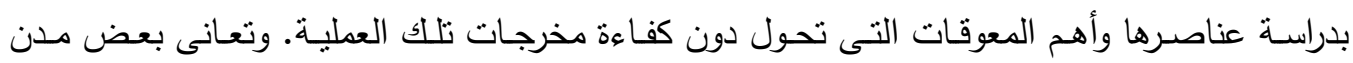

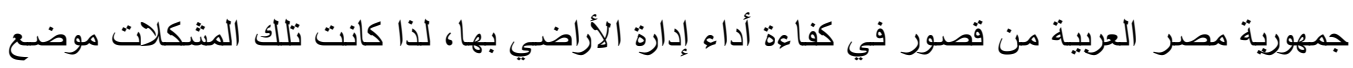
إهتمام الدراسات التخطيطية.

تعانى مدينة أسيوط من بعض المشكلات في إدارة الأراضي، أدت إلى بعض المشكلات العمرانية، والتى التى

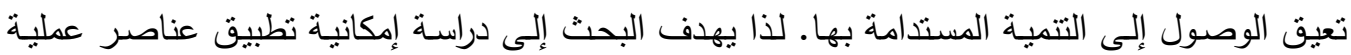
إدارة الأراضي بأسيوط، للمضي قدما تجاه تحقيق التتمية المستدامة بها.

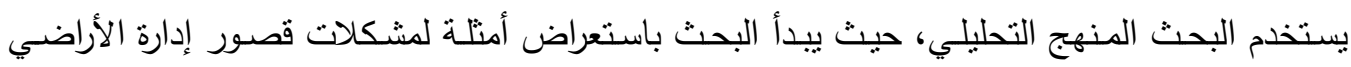

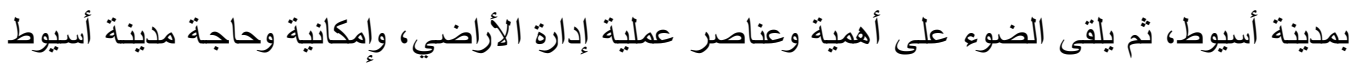
لتطبيق تلاك العناصر بها، ثم الخروج ببعض التوصيات للوصول إلى منظومة إدارة أراضي ناجحة بها.

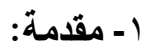
تعتبر الأرض أحد أهم الموارد الطبيعية غير المتجددة، والتى إذا نم إدارتها بشكل مناسب وجيد، سيساعد

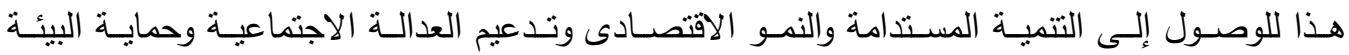

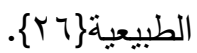
لقد أصبحت عملية إدارة الأراضي الحضرية من أهم ركائز عملية الإدارة الحضرية الجيدة، وبالتالى أحد

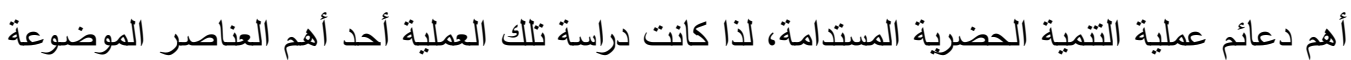

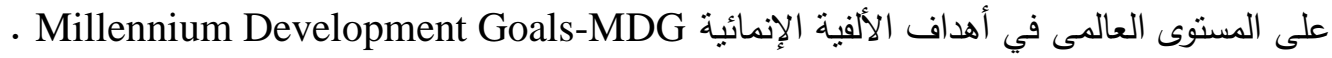
تقع مدينة أسيوط بالسهل الفيضي على الضفة الغربية لنهر النيل في النطاق الأوسط من محافظة أسيوط

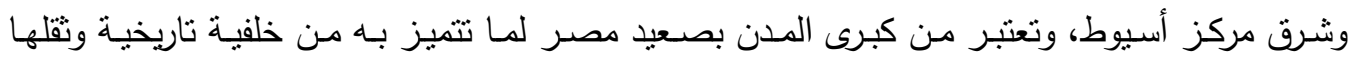

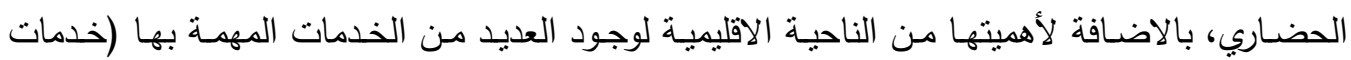

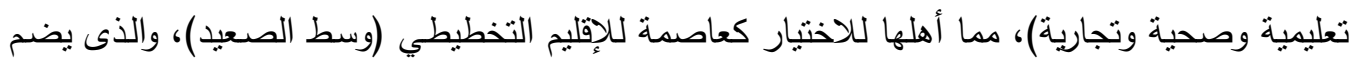
كلا من محافظتى أسيوط والوادي الجديد.

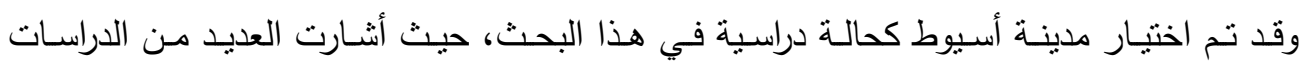

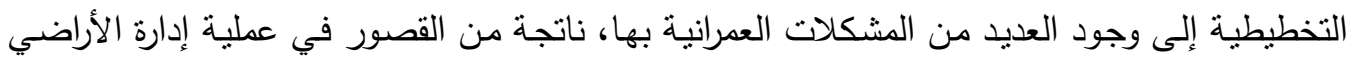




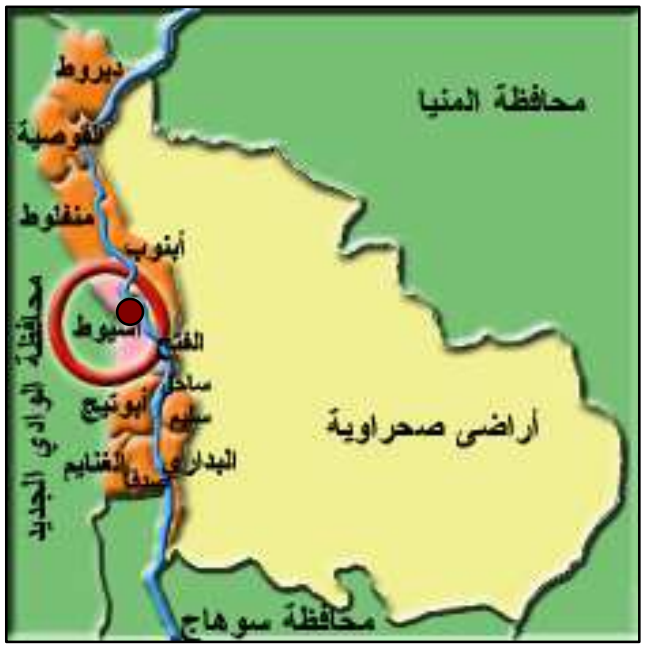

شكل رقم ( ) موقع مدينة أسيوط بالنسبة لمحافظة أسيوط والمحافظات المجاورة

1- 1- 1 - إثكالية الاراسة:

تتلخص المشكلة البحثية في وجود قصور واضح في عملية إدارة الأراضي بمدينة أسيوط، مما أدى إلى الى الئل

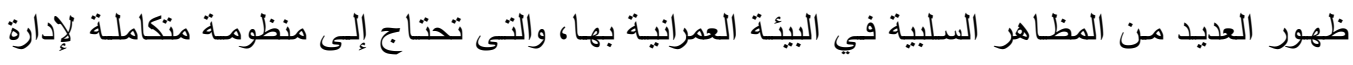
الأراضي للحد من تلك المشكلات.

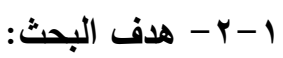

يهدف البحث إلى دراسة إمكانية تطبيق عناصرعملية إدارة الأراضي بمدينة أسيوط، للحد من مشكلات قصور إدارة الأراضي بها.

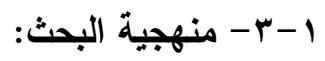

يستخدم البحث المنهج التحليلي، حيث يستعرض البحث أمثلة لمشكلات قصور إدارة الأراضي بمدينة

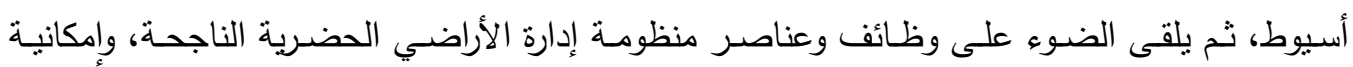

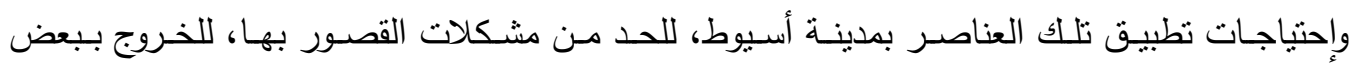
التوصيات للوصول إلى منظومة إدارة أراضي ناجحة بأسيوط، تساهم في الحد من المشكلات العمرانية

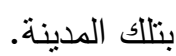

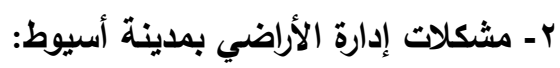
يمكن تلخيص أبرز المظاهر السلبية في البيئة العمرانية بالمدينة كالتالي: بالئية 


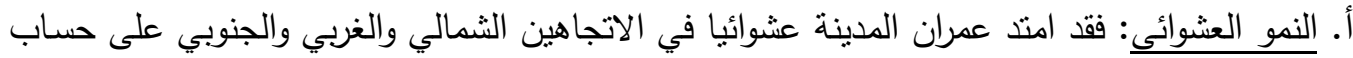

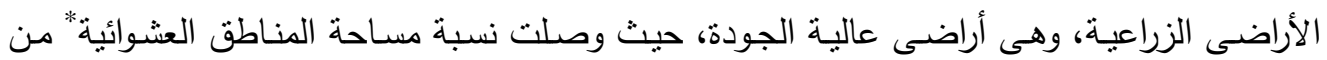

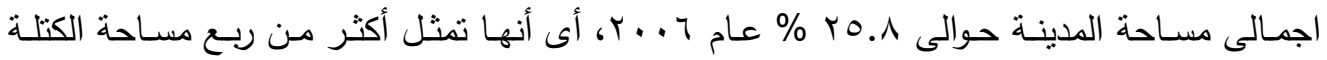

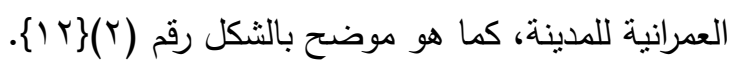

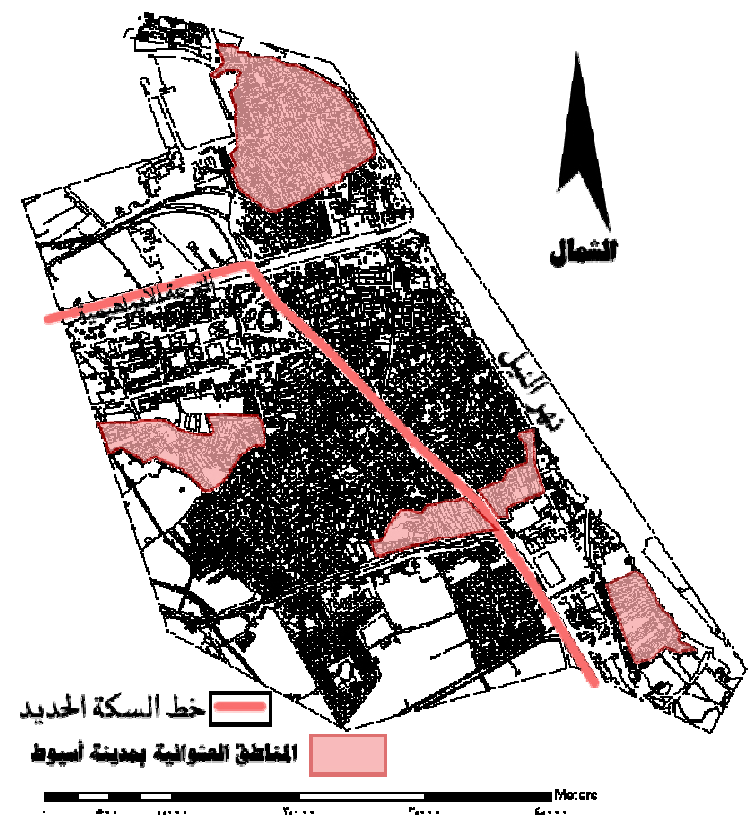

شكل رقم (ץ) المناطق العشوائية بمدينة أسيوط

ب. خلل توزيع الاستخدامات: والذي يتمثل في وجود بعض الاستعمالات في مواقع غير مناسبة، كوجود

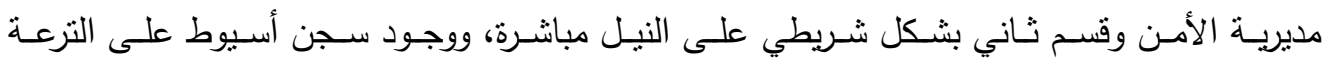

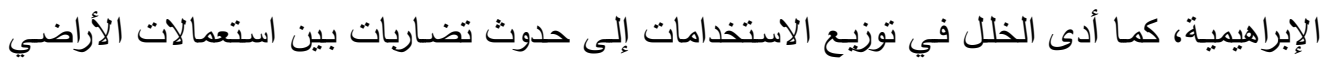

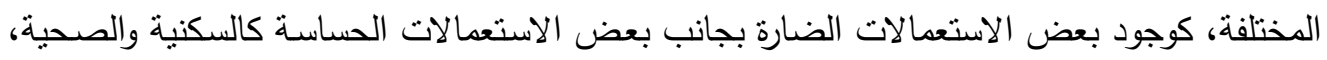

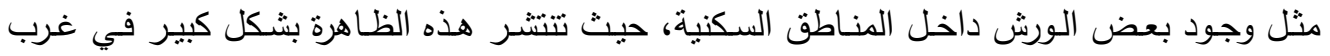

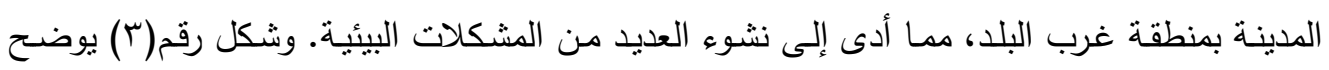
بعض الأمثلة للقصور في اختيار مواقع الاستخدامات الأمنية بمدينة أسيوط.

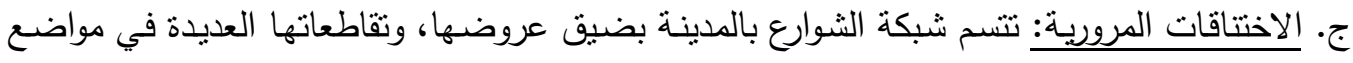

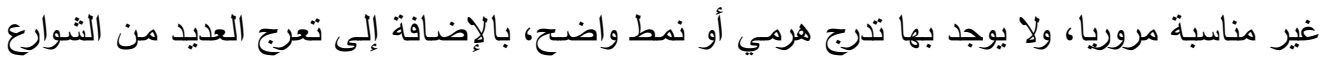

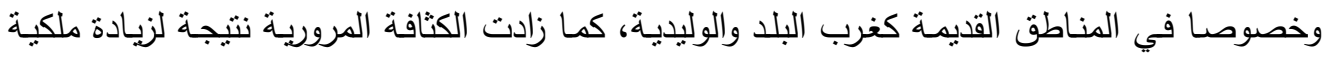

* يقصد بالمناطق العشو ائية (كما عرفتها هيئة الأمم المتحدة) هى المناطق التى بنيت بطريقة غير رسمية أو المحرومة من المر افق أو الثديدة التدهور. 
السيارات بالمدينـة بشكل كبير مـع مـرور الوقت، فعلى سبيل المثال زادت ملكيـة السيارات بحوالي

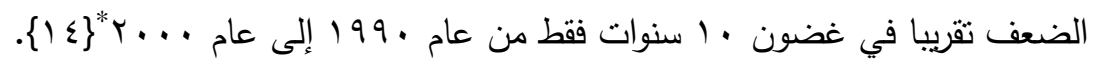

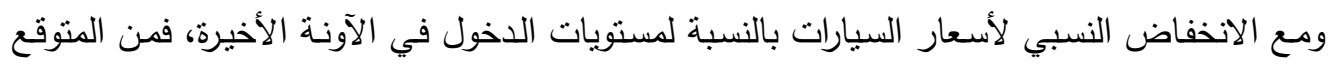
تضاعف معدلات ملكية السيارات في السنوات القادمة.

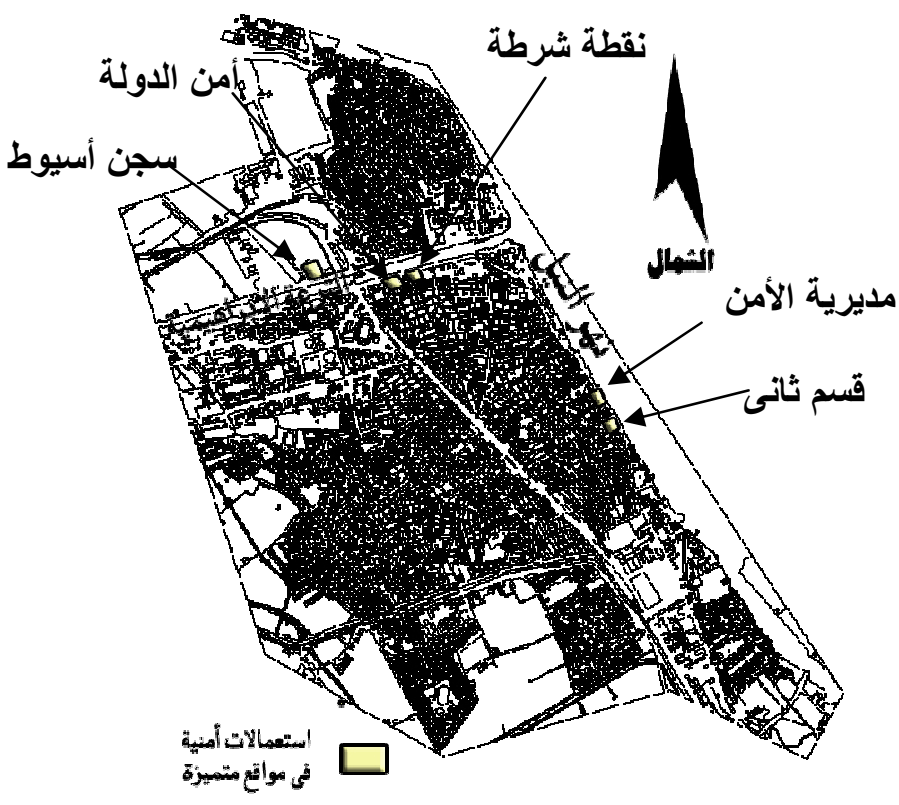

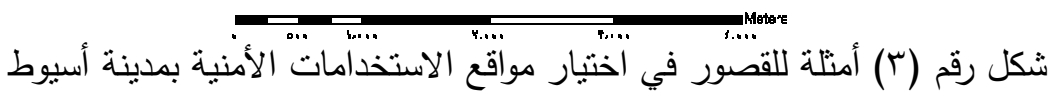

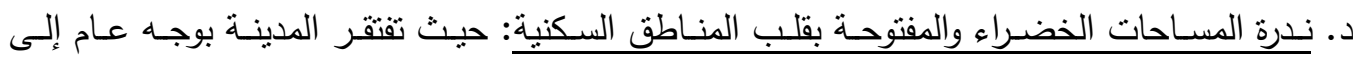

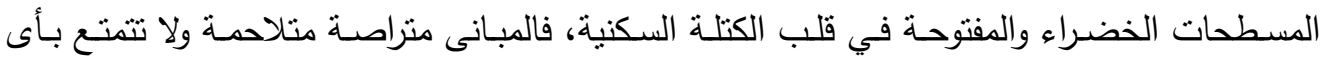

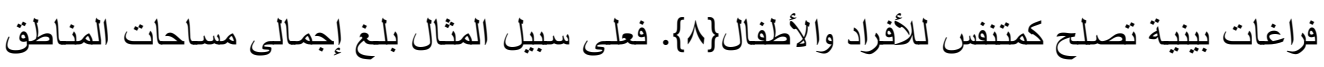

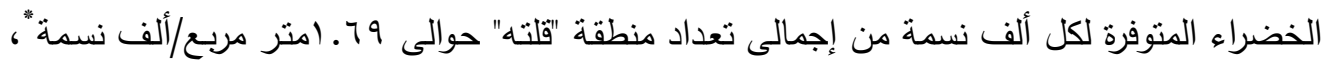

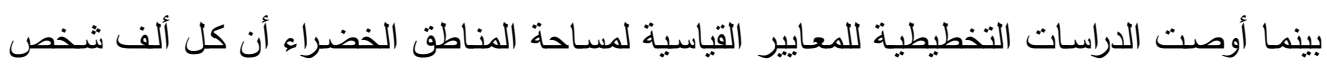

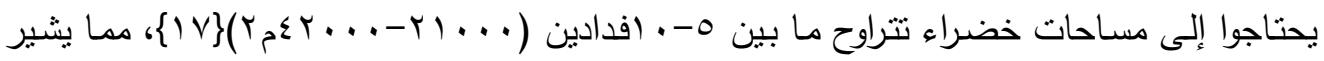

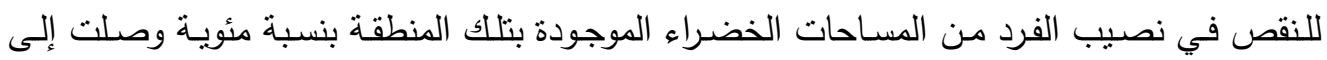
حوالى 9 9 \%، إلى جانب تركزها بالجزء الثمالى بالمنطقة، أى أن المناطق الخضراء تكاد تتعدم بتلكئك

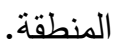

*لا توجد بيانات متوفرة حديثة عن حجم ملكية السيارات بإدارة المرور عن مدينـة أسيوط نفسها، نظر الأن قاعدة البيانات

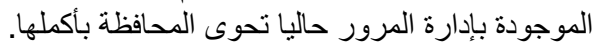

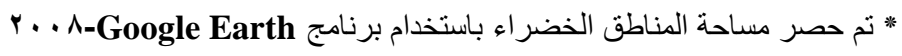


كما تتبع كل من مشكلتي الاختناقات المرورية و ندرة المساحات الخضراء والمفتوحة مشكلات تلوث

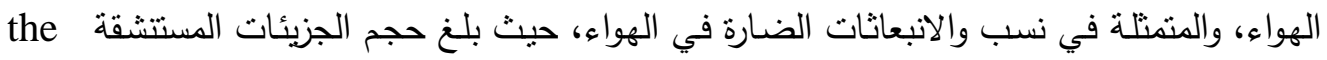
Breathed Particles PB

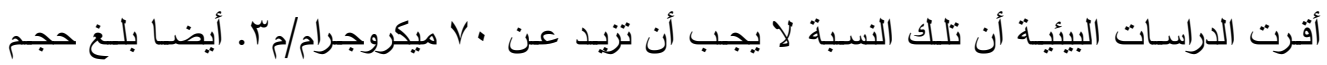
الجزيئات العالقة في الهواء 462 ميكروجرام/مَ في محافظة

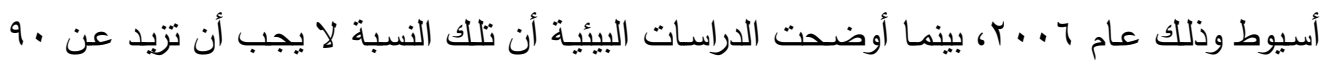

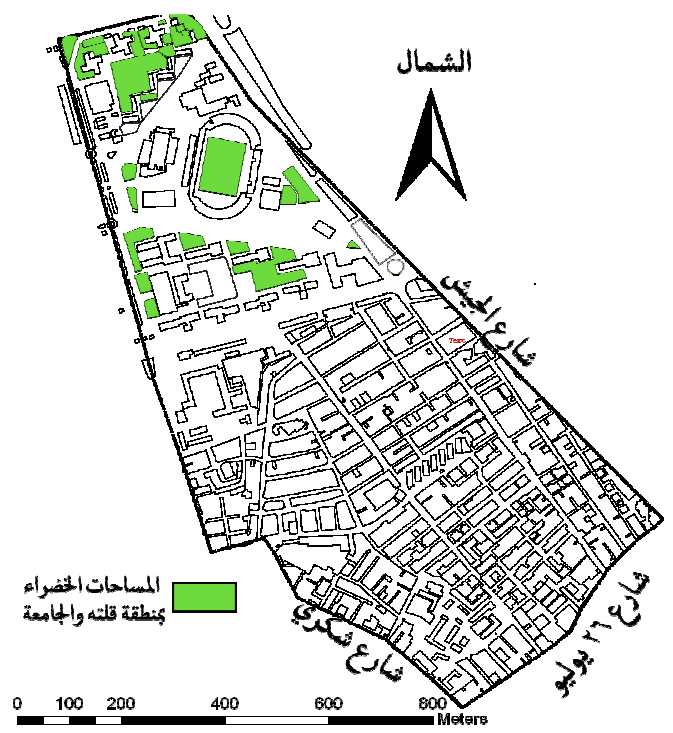

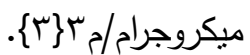

شكل رقم (ع) المساحات الخضراء المنوفرة بمنطقة قلته والجامعة

هـ. الضوضـاء: نتيجـة وجود بعض الاستعمالات الحساسـة كالسكنية والصـية داخل الكتلـة العمرانيـة

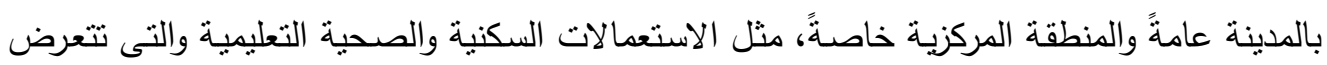

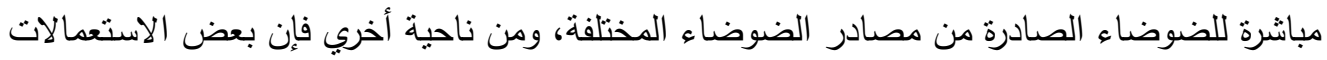

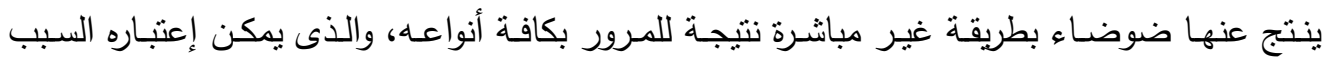
الرئيسي للضوضاء بالمدينة.

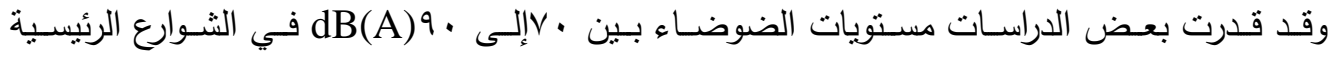

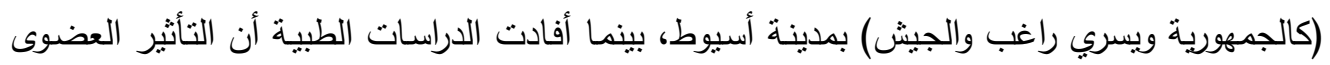

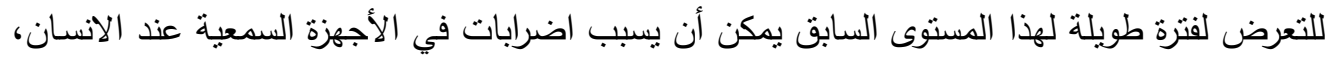

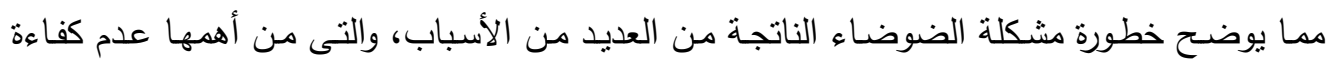


توزيع استعمالات الأراضي بالمدينة والحركة المرورية غير المتتاسبة مع درجة استيعاب شبكة الطرق والشوارع بالمدينة\}؟ 1).

و • القصور الثـديد في تخطيط منطقة وسط الددينة: حيث تعاني منطقة وسط المدينـة من مشـاكل

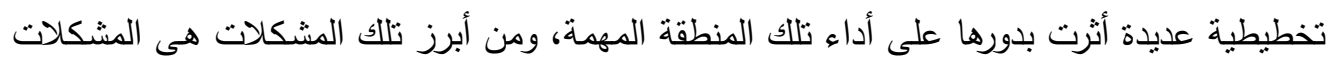

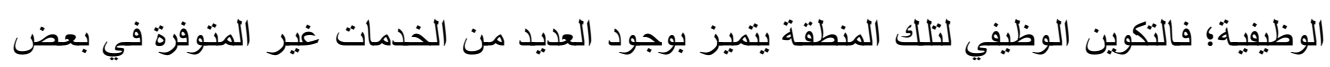

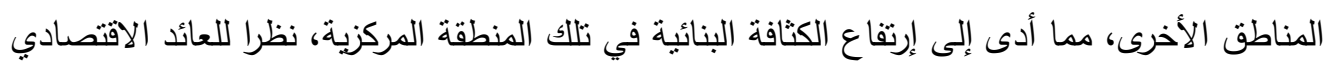

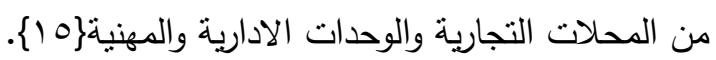

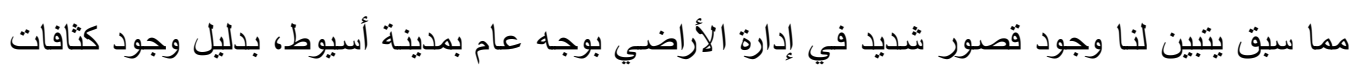

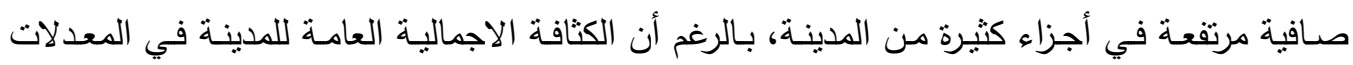

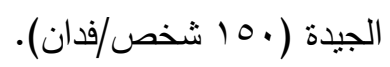

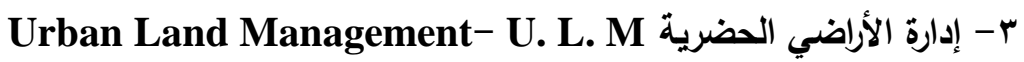
أصبحت إدارة الأراضي في الآونة الأخيرة من أبرز الدجالات التخطيطية، وذللك لأهمية وحيوية الأراضي

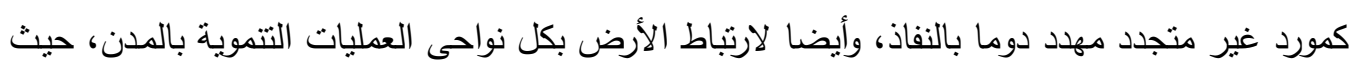
أن الأرض هى قاعدة كل مشروع تتموي بأى مدينة. r-1- ب-مفهوم ادارة الأراضي الحضرية:

إن إدارة الأراضي هو لفظ شامل للأنشطة التى تهدف إلى تلبية الأهداف التتموية من خلال توظيف

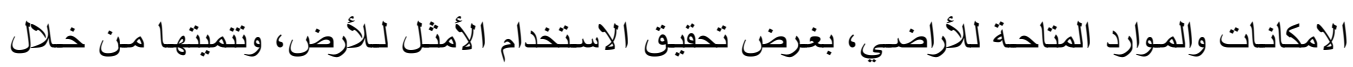

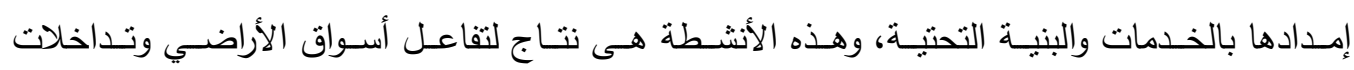

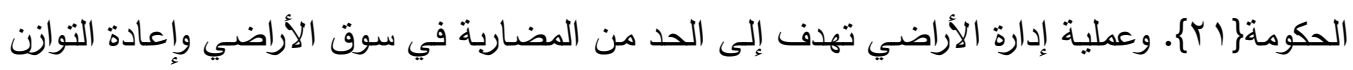

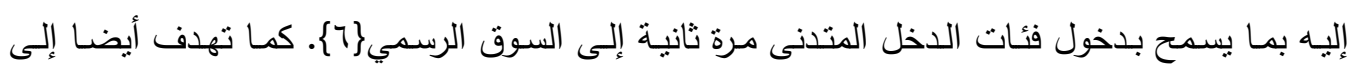

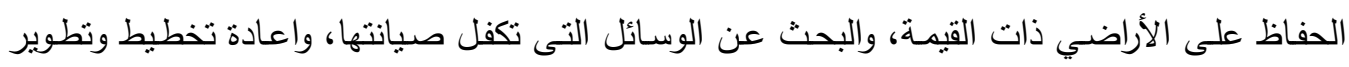

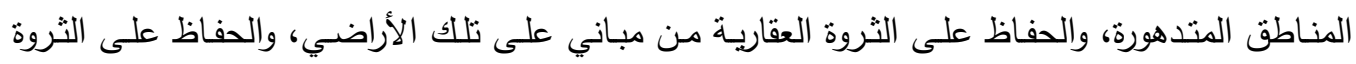

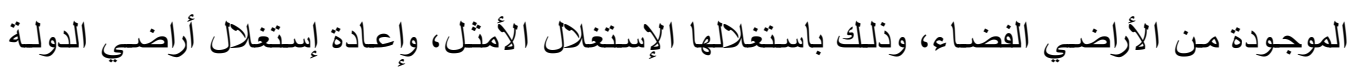
الموجودة في مناطق وسط المدينة وداخل الكتلة العمرانية\} • 1\{. r-r - قضايا الأراضي كأحد ركائز الإدارة الحضرية:

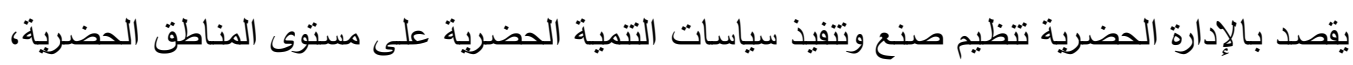

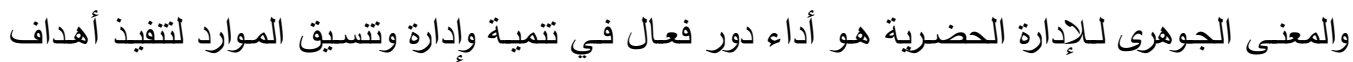
التتمية الحضرية\}ي (1). 
وتعتبر إدارة الأراضــي أحـد أهم ركائز الادارة الحضـرية الجيدة بجانب بـاقى الركائز مـن بـرامج الاسكان

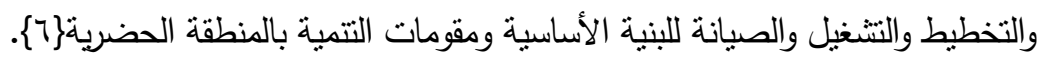

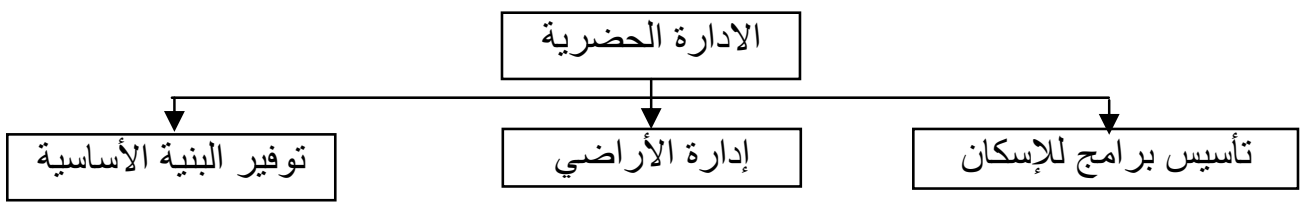

شكل رقم (0) ركائز الإدارة الحضرية

ب-r- الفرق بين التحكم في الأراضي وإدارة الأراضي:

يتضح الفرق بين كل من التحكم في الأراضي وإدارة الأراضي من خلال تعريفهما:

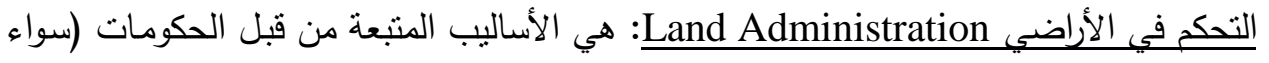
كانت مركزيـة أو محليـة)، في إدارة حقوق وقيم وملكيات ومعلومـات الأراضـي ونظم الضـرائب والقروض لها.

إدارة الأراضي Land Management: هي المنهجية المتبعة للوصول لأكفأ استغلال للأراضي

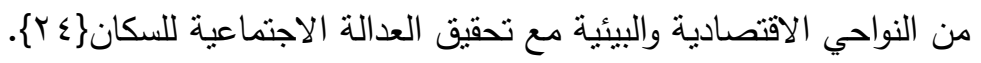

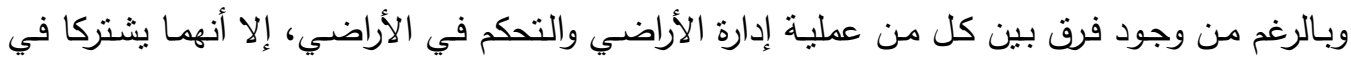

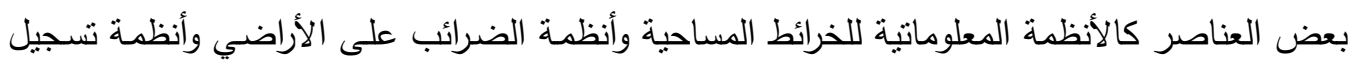

الأراضي، كما هو موضح في شكل رقم (ج).

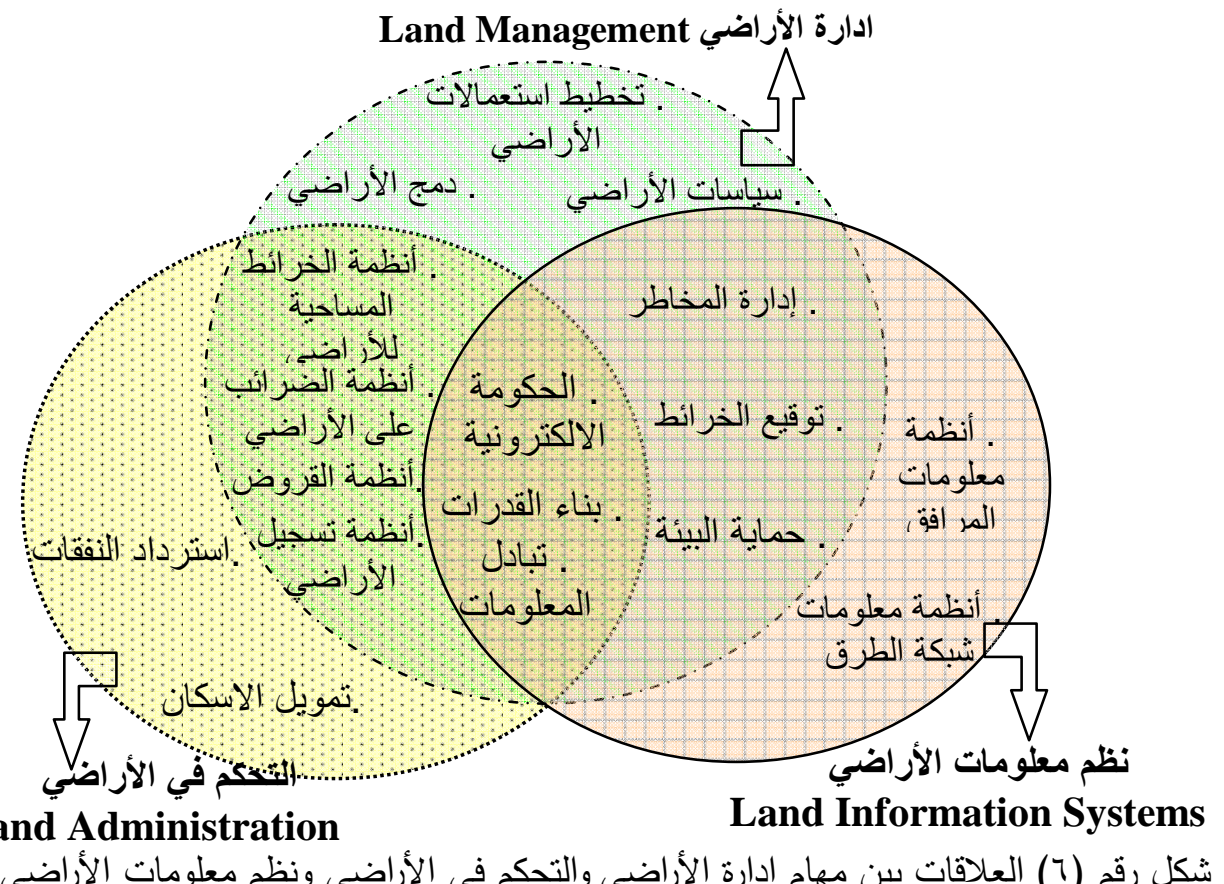

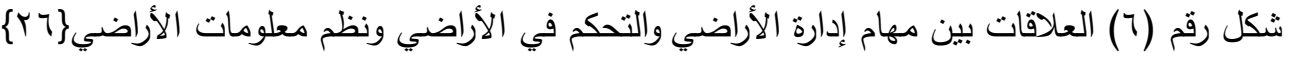


U. L. M. Components ب- ع-عناصر عملية إدارة الأراضي الحضرية

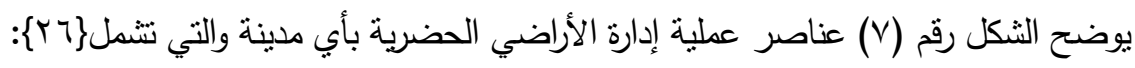

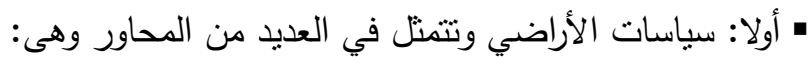

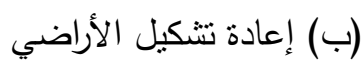

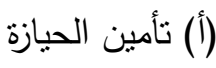
(د) الأنظمة الضريبية على الأراضي لتيكي الاراضي

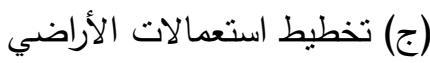
(و) (إدارة أسواق وأسعار الأراضي الاضي الاراضي (هـ) (أنظمة القروض والتمويل (ح) (إدارة المناطق غير الرسمية والار الراطية (ز) تزويد الأراضي بالخدمات وشبكات المرافق

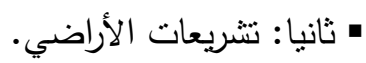

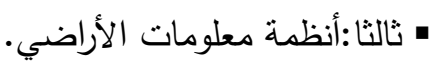

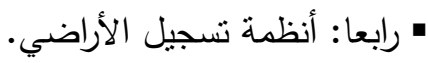
• خامسا: النظام المعلوماتى للخرائط المساحية. • سادسا: حماية البيئة الطبيعية للأراضي. وبشكل عام أنشارت بعض الدراسات أن هناك ارتباطاً وتأثيراً منبادلاً بين عناصر إدارة الأراضي وبعضها

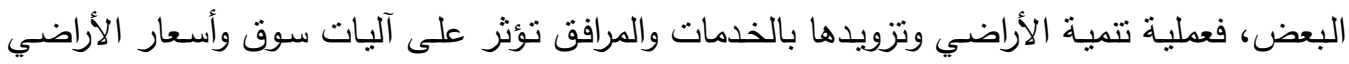

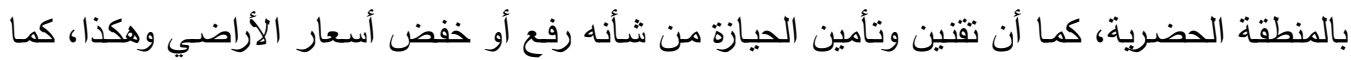

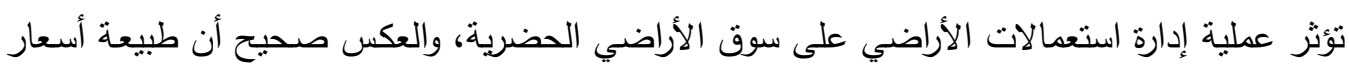

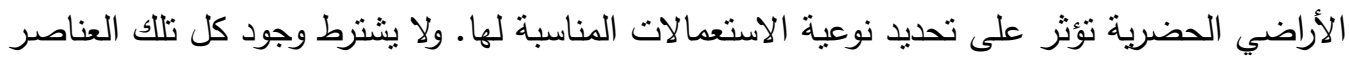
في كل عملية إدارة أراضي ناجحة، بل يتوقف الأمر على احتياجات كل مدينة.

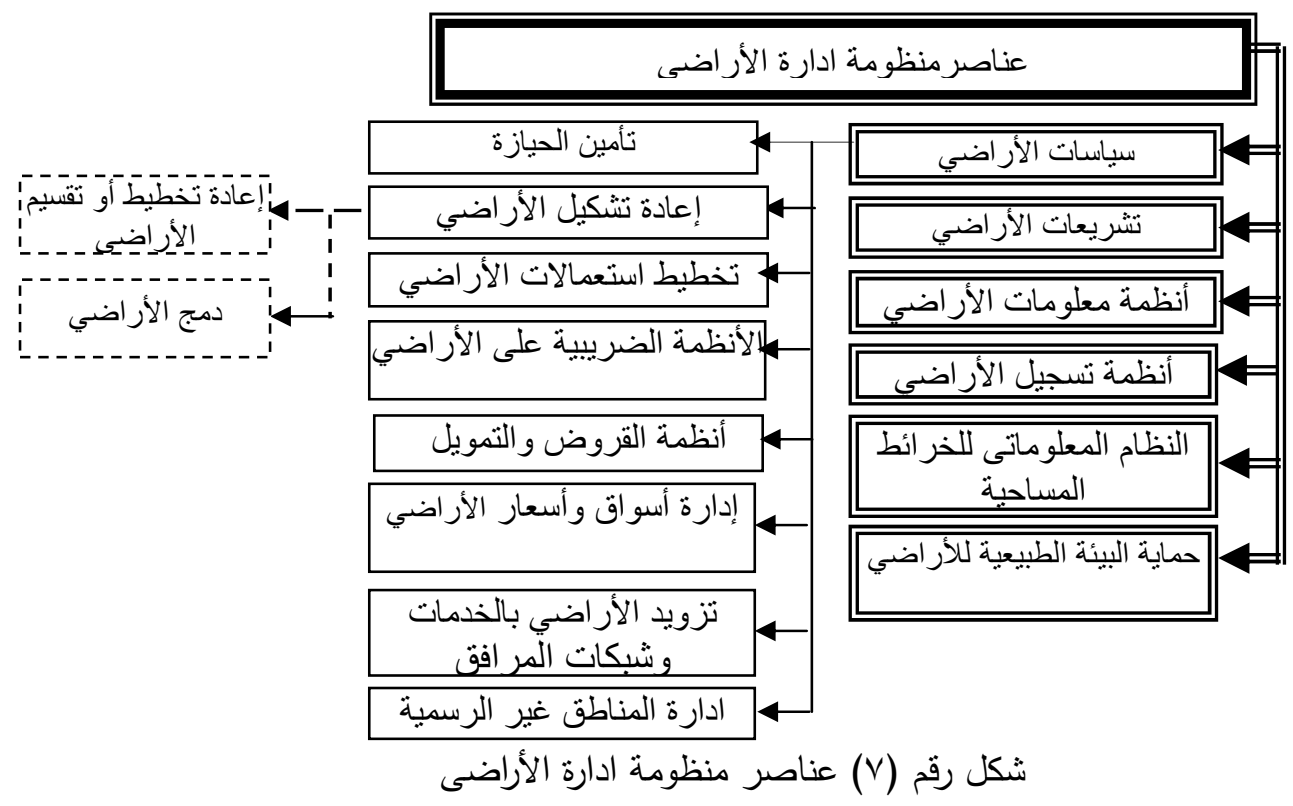


r-ه - وظائف إدارة الأراضي الحضرية:

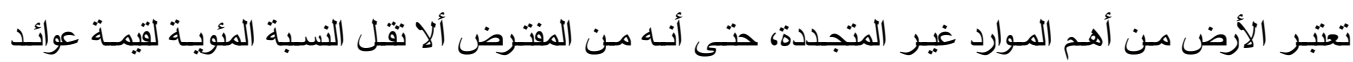

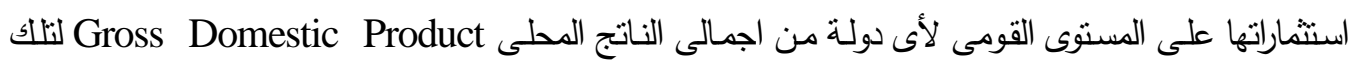

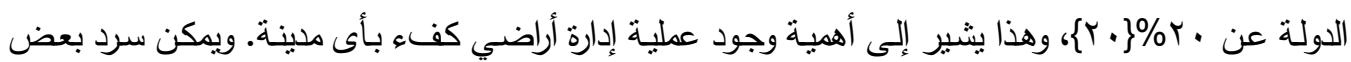
وظائف عملية إدارة الأراضي لتوضيح أهميتها كالتالى: أ. حفظ وضمان الملكية وتأمين الحيازة. ب. تدعيم عمليات النقييم بنظام الضرائب على الأراضي. ج. حماية رؤوس الأموال. د. ت تطوير ومتابعة أسواق الأراضي. هـ - مـاية أراضي أملالك الدولة.

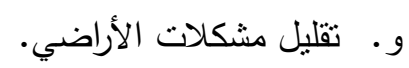

ز. . تحسين عملية التخطيط العمرانى وتتمية البنية التحتية.

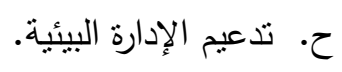
ط. بناء قواعد بيانات احصائية مختصة بقضاياء الأراضي.

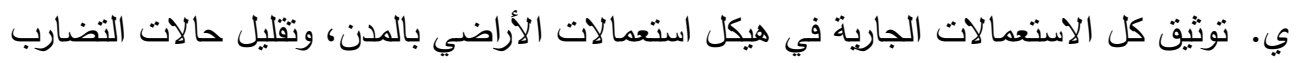
بين نوعيات الاستعمالات المختلفة.

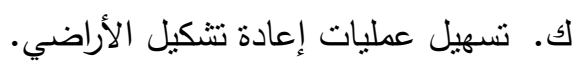

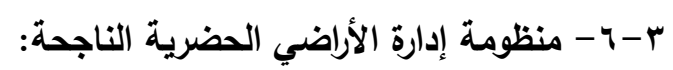

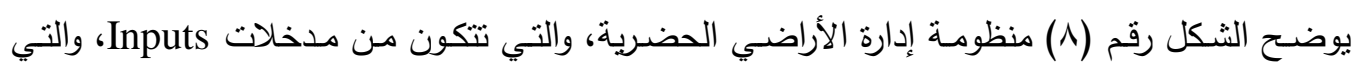

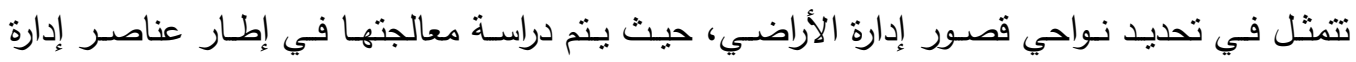

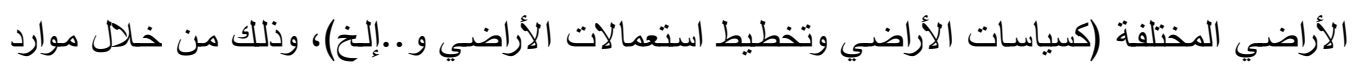

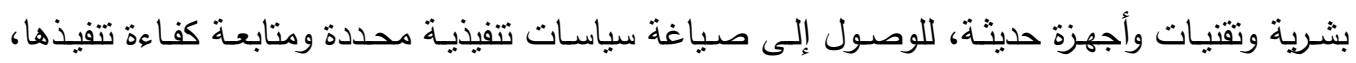
للوصول للمخرجات Outputs من نتائج مختلفة.

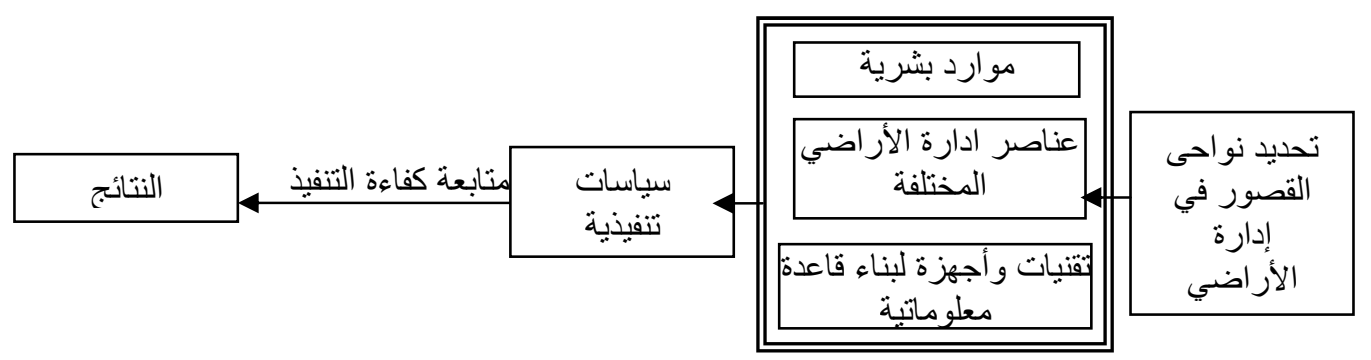

شكل رقم (^) منظومة إدارة الأراضي الحضرية 
إن عملية إدارة الأراضـي الناجحة لابد وأن تقوم على ركيزة من المعرفة، والمعرفة عبارة عن الأنظمـة

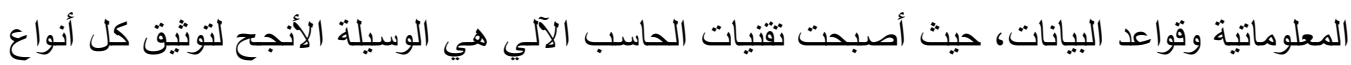

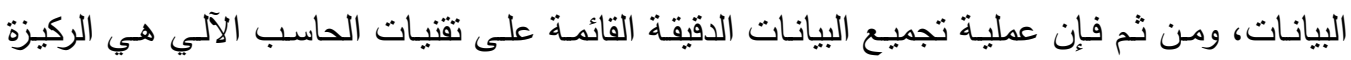
الأساسية لإدارة الأراضي الناجحة. كما أن الموارد البشرية الجيدة تمثل ركيزة هامة لتحقيق إدارة أراضي جيدة بشكل عام، وعمليات تجميع الإضي

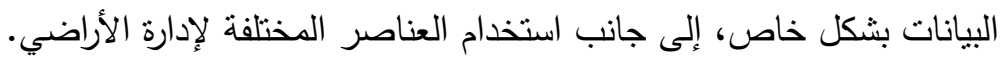

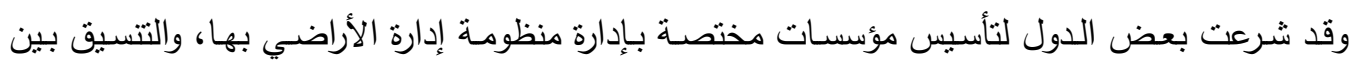

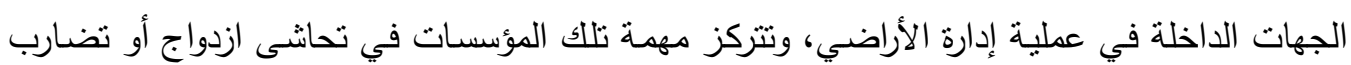

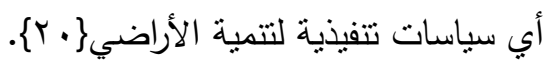
كما أثتبت التجارب العملية أن الحكومات بمفردها لا نستطيع أن تدير الأراضي بطريقة ناجحة، ولكن

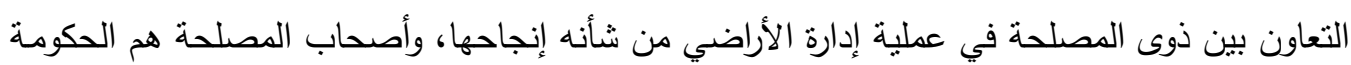

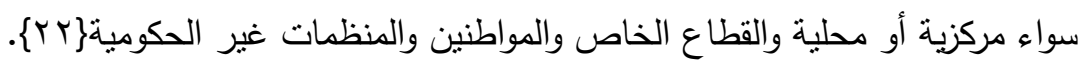
؟ - عناصر إدارة الأراضي وإمكانية تطبيقها بمدينة أسيوط:

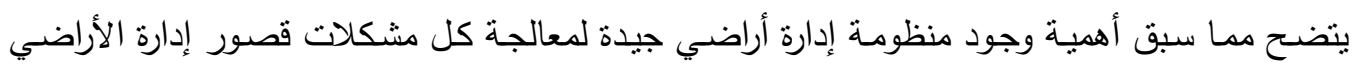

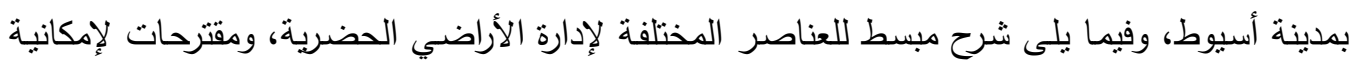
تطبيق كل عنصر من عناصر منها بمدينة أسيوط للحد من المشكلات العمرانية بها.

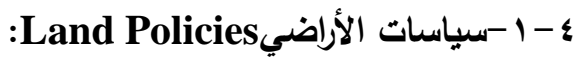
هي السياسات التي تتنهجها الحكومات بهدف تحقيق التوازن بين الاستفادة العظمى من الأراضي والحفاظ عليها كمورد غير متجدد للوصول إلى التتمية المستدامة، وتتكون سياسات الأراضي من العديد من الأوجهـ

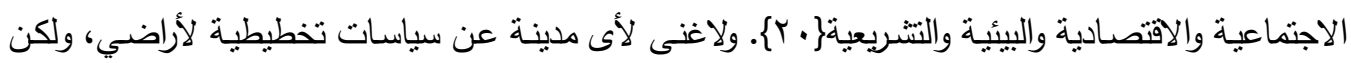

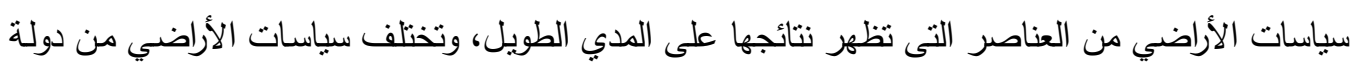

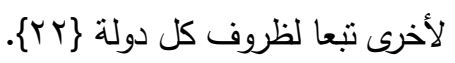
وبالنسبة لمدينة أسيوط فللوصول إلى سياسات تخطيطية ذات جدوى يجب أن يتم صياغة تللك السياسات بواسطة مجموعة من أصحاب المصلحة، ومنهم خبراء في مجال إدارة الأراضي والإدارة المحلية الهيئة

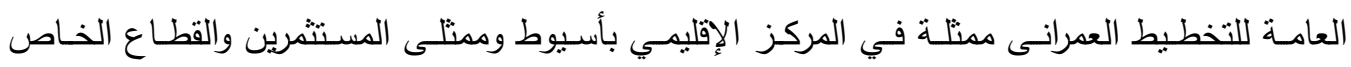
والمنظمات غير الحكومية. وفيما يلى استعراض لمحاور سياسات الأراضي وامكانية تطبيقها بمدينة أسيوط: 
(أ) تأمين الحيازة Land Secure Tenure إن عملية تأمين الحيازة (تقنين الأراضي) عن طريق توثيق حق الملكيات تؤثر في كفاءة إدارة الأراضي،

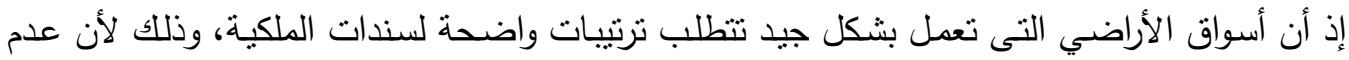

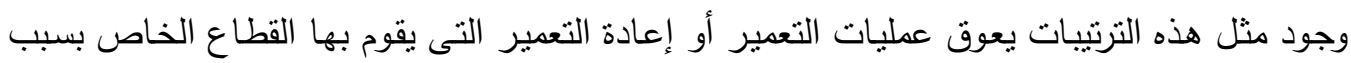
تعريض المكاسب التى ينوقعها للخطر، فعندما يكون بالمدينة قطاع غير رسمي تكون فيه حقوق استخدام

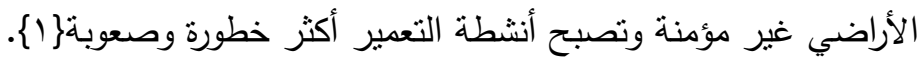

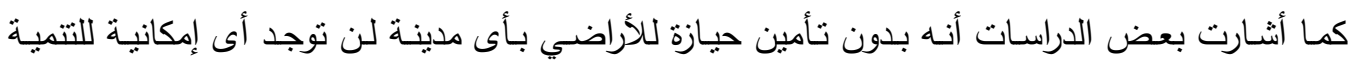

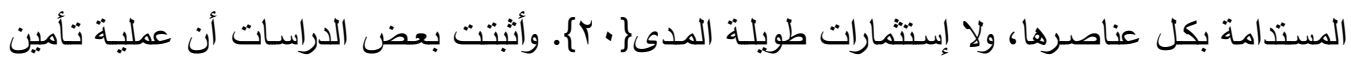

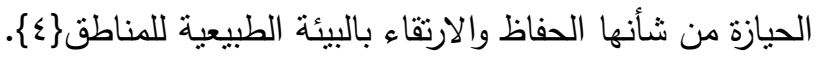

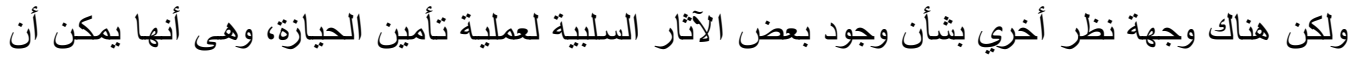

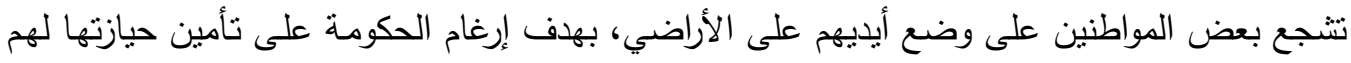

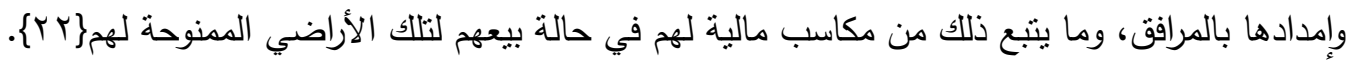
لذا يجب أن تتم عمليات التقنين وفق ضوابط صارمة لحماية حق الدولة في حالة نقل الملكية من السكان المقنن ملكيتهم إلى طرف ثالث، وذلك لتوجيه هذا الحق في نصيب الدولة في نقل الملكية لطرف ثالث

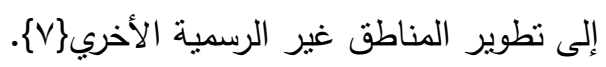

وبالنسبة لمدينة أسيوط تمثل المناطق غير الرسمية نسبة كبيرة من مساحة الكتلة العمرانية للمدينة، لذا

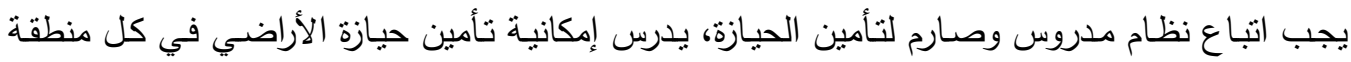

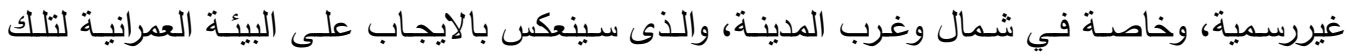

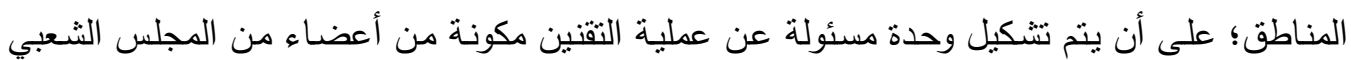
المحلى والتتفيذين بالمدينة من الجهات الأمنية والقائمين على صياغة المخططات العمرانية للمدينة من مسئولى التخطيط العمرانى بالمحافظة والمركز الاقليمي للهيئة العامة للتخطيط العمرانى، وأيضا مديريات المرافق والخدمات بالددينة، ليتسنى تتاسب عمليات التقنين مع المخططات العمرانية والطاقة الاستيعابية لمرافق وخدمات المدينة، مـع مراعاة متابعة عمليات إعادة نقل الملكيات حتى لا تكون عمليـة تأمين

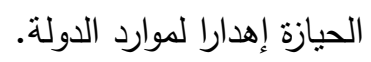

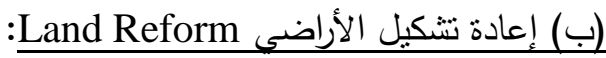

تعتبر عمليـة إعـادة تتـكيل الأراضـي مـن أهم عناصـر إدارة الأراضـي، وتشـمل عمليـة إعـادة تشكيل

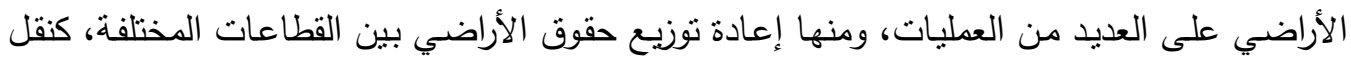

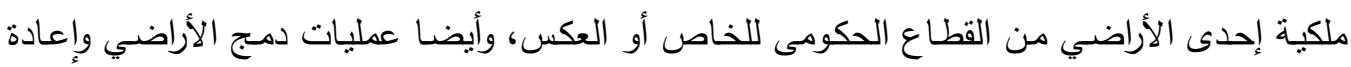


تخطيط وتقسيم المناطق وغيرها، وسنستعرض بالتفصيل هنا أهم عمليتين في عمليات إعادة تثكيل الأراضي وهما:

ا ـ إعادة تخطيط أو تتظيم الأراضي: إن اعتبار المنفعة العامة لسكان المدينة ككل هو أساس عملية إعادة تخطيط الأراضي، إلا أنه بوجه عام يجب عمل نوازن بين المنفعة العامة وبين وجهة نظر الملاك لاستعمال

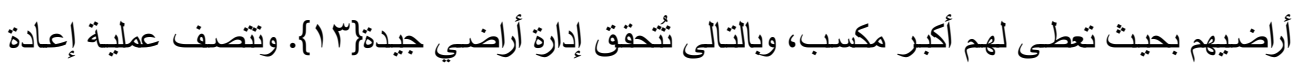

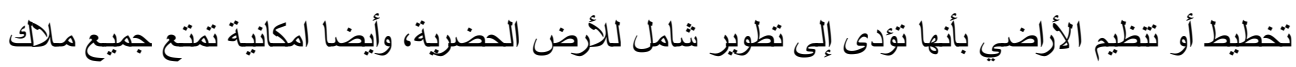
قطع الأراضي بفوائد عملية إعادة التخطيط بشكل متعادل في أبي منطقة، كذلك إمكانية مشاركتهم في المرحلة

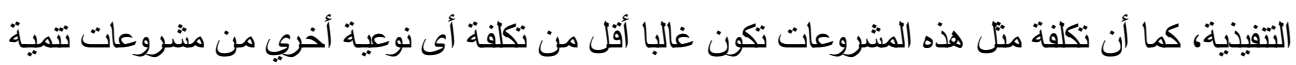
الأراضي\} (1)

وتوجد العديد من المناطق في شمال وغرب أسيوط في حاجة ماسة لعمليات إعادة التخطيط من خلاد

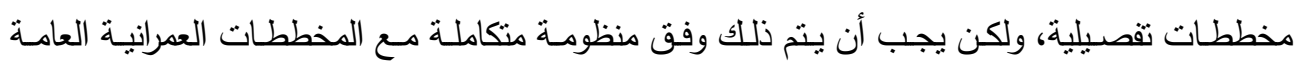
والتفصـيلية للمدينـة، حيث تم استـحداث نظـام التخطبط الاستراتيجي في العطليـات التخطيطيـة للمدن

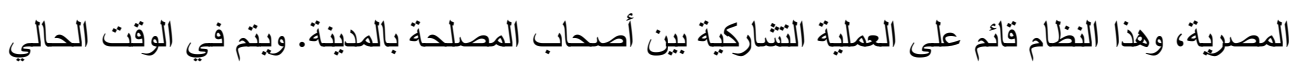

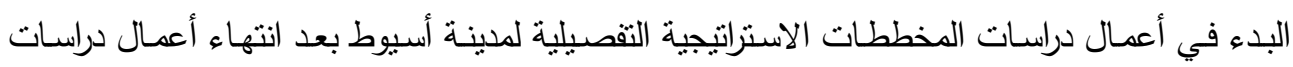

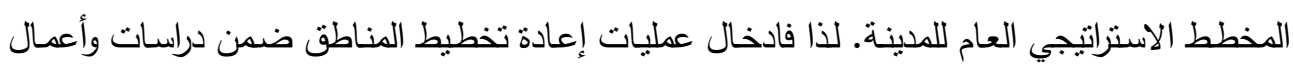
المخططات التقيلية الاستراتيجية للمدينة من شأنه تحقيق الاستفادة لأكبر عدد ممكن من الأطراف.

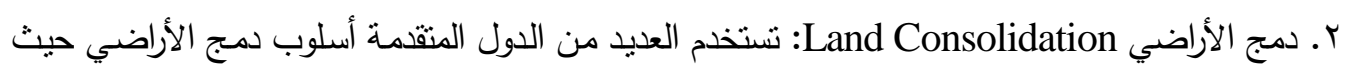

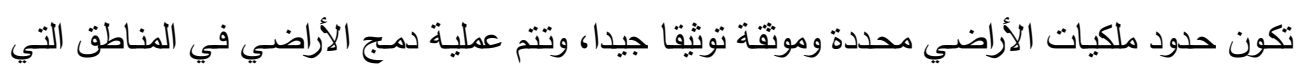

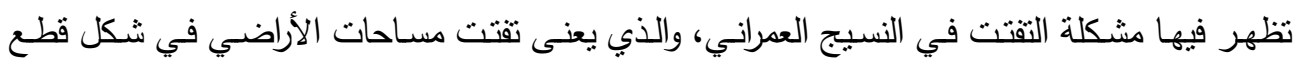

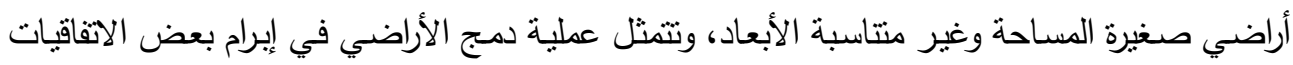

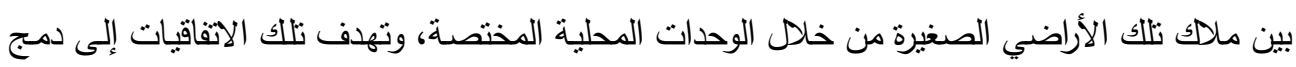

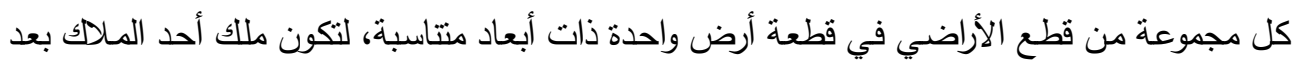

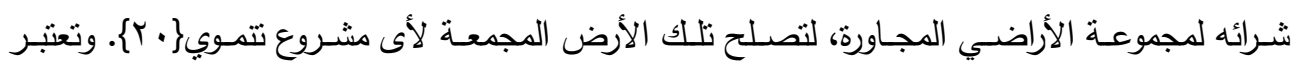

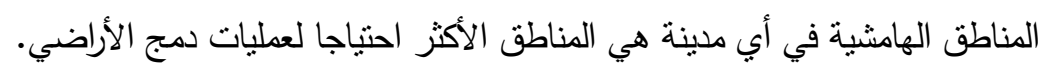

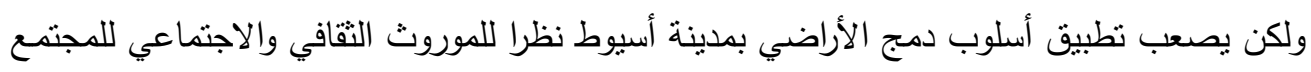
وصعوبة تتازل المواطنين عن أراضيهم لدمجها.

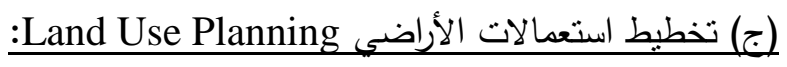

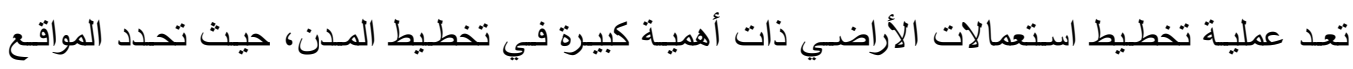
الجغرافية لأنشطة المدينة المختلفة وتحدد طبيعة العلاقة بينها، لذا فعطلية صياغة السياسات التخطيطية 
لتركيب استعمالات الأراضـي بـأى مدينة يمكن أن تؤدي إلى الوصول لأقصى درجـة كفاءة استخدام لكأراضي بها\} 11 1).

وقد نص قانون البناء الموحد الجديد الصادر في مايو ر . . ب بأن تقوم الهيئة العامة للتخطيط العمرانى

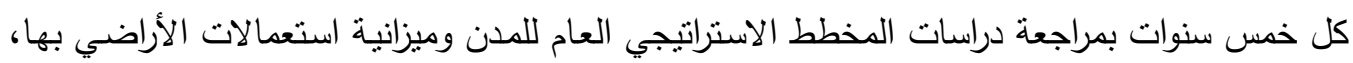

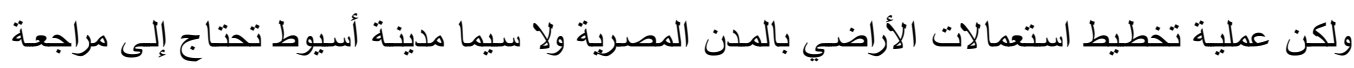

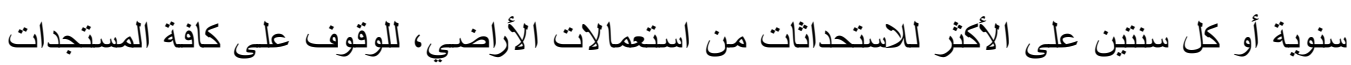
من احتياجات المدينة من بعض الاستعمالات المعينة.

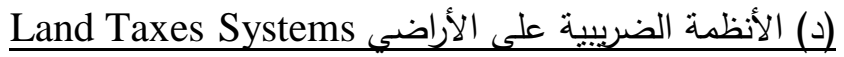
تعتبر الأنظمة الضريبية هى الأنظمة المتبعة من قبل الدولة لجمع الموارد المالية من فئات محددة من

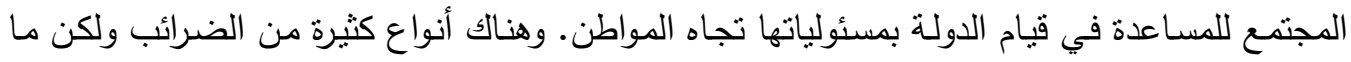

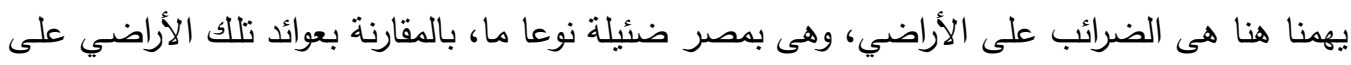
مستثريها. يمكن استخدام النظام الضريبي على الأراضي كأداة للعمليات التتموية بمدينة أسيوط عن طريق اقرار

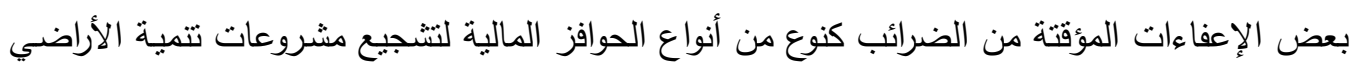

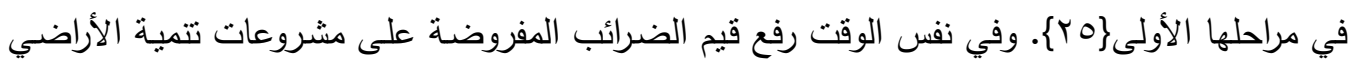

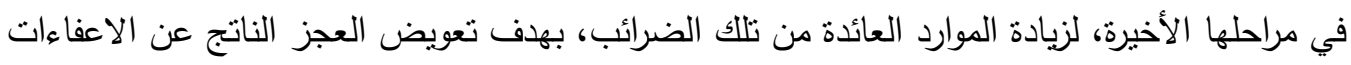

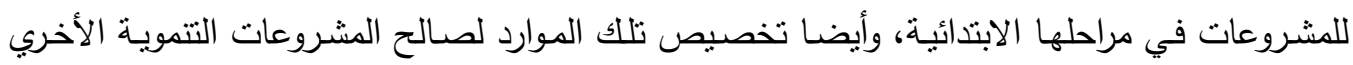
لأراضي المدينة.

Mortgage and Credit Systems هـ) أنظمة القروض والتمبيلهيل

هـي الأنظمـة المتبعـة مـن قبل المؤسسـات التمويليـة كالبنوك والمؤسسـات الاجتماعيـة الدوليـة والقوميـة لتتجيع المشروعات التتموية، وتعتبر أنظمة القروض من أكثر السياسات التى تشجع العمليات التتموية للأراضي، شريطة أن تكون بنسب فائدة معتدلة. تحتاج مدينة أسيوط للعديد من المشروعات التتموية الخدمية للأراضي ومشروعات تقسيم الأراضي بالمناطق

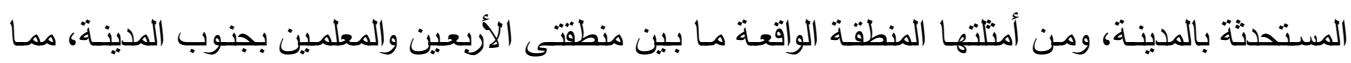

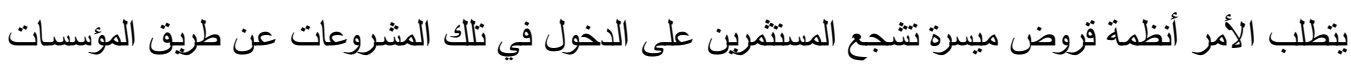
النتويلية والمؤسسات الاجتماعية الدولية والقومية".

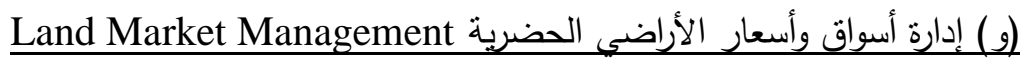

* يوفر بنك الإسكان و التعمير بمدينة أسيوط قروض لراغبى بناء الإنثاءات السكنية وخلافه، ولكن لا يوجد نظام تمويلي

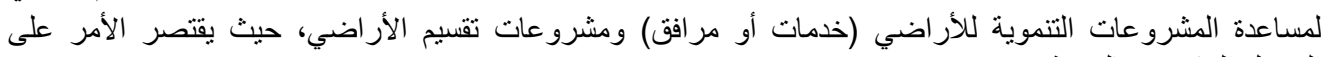
التمويل الحكومي بالمدينة. 
تؤثر اقتصاديات السوق على استتمارات الأراضي بشكل جوهرى، فيجب أن تُكم أسواق الأراضي بقواعد

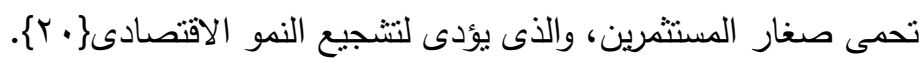
إن آليات السعر يسبب تغيرات في طبيعة الكثافات بالأراضي الحضرية، ويري الاقتصاديون أن أسعار

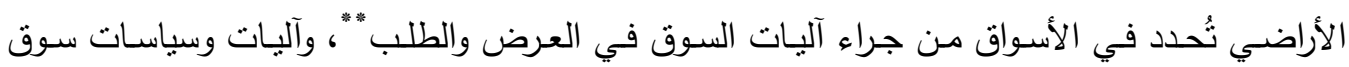

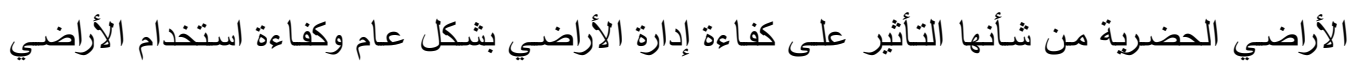
بشكل خـاص، فنظام السعر بأى منطقة حضرية يلعب الدور الدحرك للأراضي ونوعيـة استعمالاتها

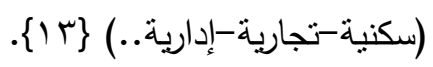

إن سعر الأرض يعتبر من أثند العوامل ثأثثرا على التتمية المستدامة بمدينة أسيوط حيث أن هناك العديد من أوجه الثأثير السلبي لسعر الأرض على الكفاءة الاقتصادية كعدم التكافئ بين الزيادة المطردة لأسعار

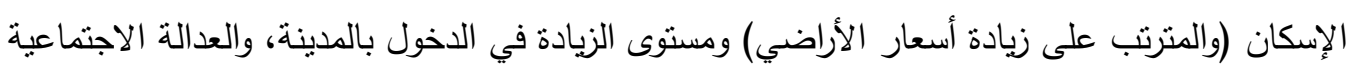

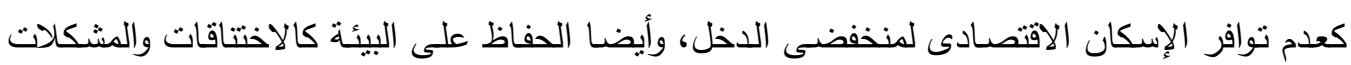

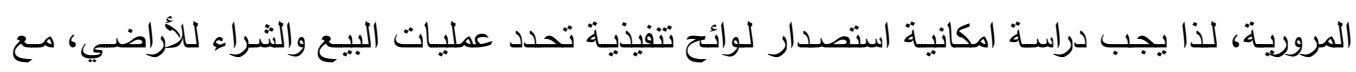
تتظيم لجنة متخصصة لمتابعة سوق الأراضي.

(ز) تزويد الأراضي بالخدمات وشبكات المرافق Land Supply with Services \&Utilities أثتتت الدراسات أن عملية توفير كل من الخدمات (تعليمية وصحية واجتماعية وتجارية وغيرها)، والبنية

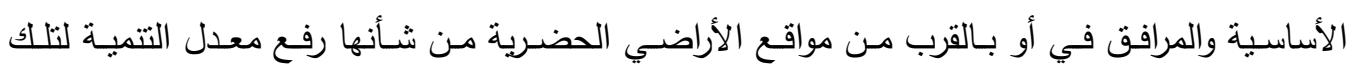

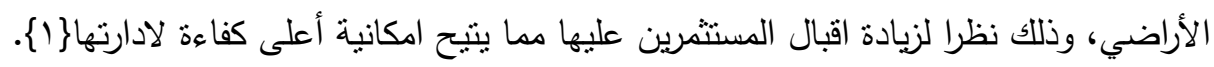

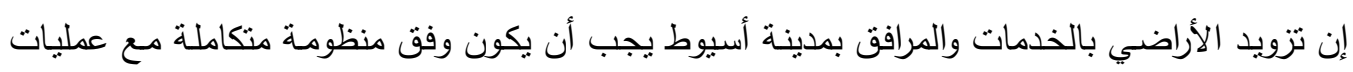

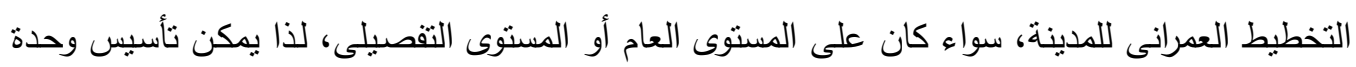
تتسيق تهدف إلى دراسة احتياجات تغطية كل مناطق المدينة بالخدمات والمرافق التى تحتاجها، تتكون تلك الوحدة من الهيئة العامة للتخطيط العمرانى والمسئولة عن مشروعات التخطيط العمرانى والادارة المحلية للمدينة والوزرات المختصة بكل نوع خدمات أو مرافق وممنلى المجلس الثعبي المحلى للمدينة.

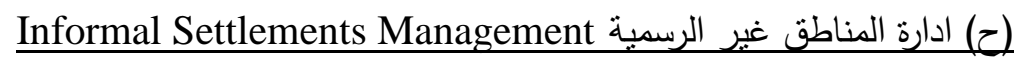
أصبحت المناطق غير الرسمية عنصراً مههاً في تكوين المناطق الحضرية بالدول النامية، نظرا لأنها

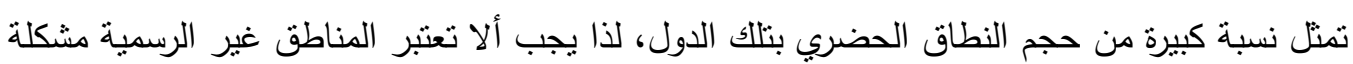

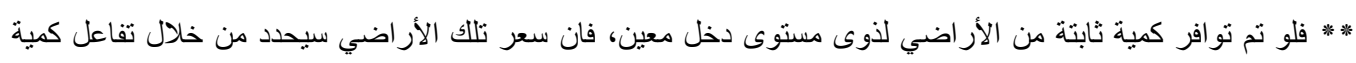

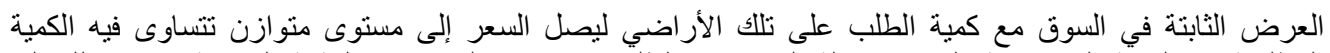

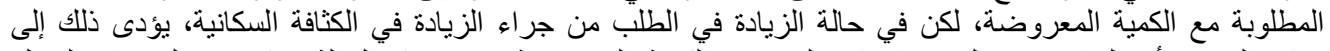

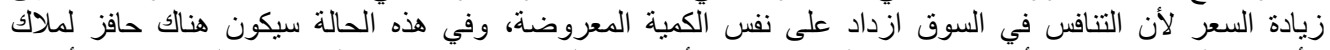

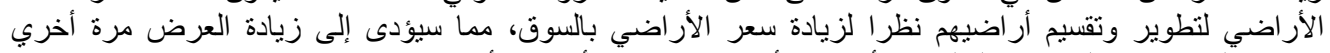
ويحدث ألتوازن بين العرض و الطلب في أسواق الأراضي فتنخفض أسعار الأراضي. 
يجب القضاء عليها، بقدر ماهى وضع قائم يجب التعامل معه كأداة تتموية، لذا بدأت تظهر إتجاهات تخطيطية جديدة تتمنل في إدارة وتطوير تلك المناطق. ويمكن إدارة المناطق غير الرسمية عن طريق منهجيتين: الأولى: تتمنل في عمليات التطوير والارتقاء والتزويد بالخدمات والمرافق المطلوبة، وتكون تلك المناطق مناسبة للمعيشة (من أمثلة ذلك منطقة الحكر بالاسماعيلية).

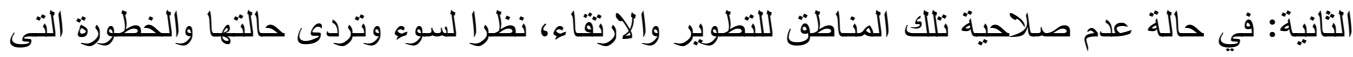
تمنلها على حياة قاطينيها وقاطنى المناطق المحيطة بها، لذا يستلزم الأمر إزالة تلك المناطق وإعادة

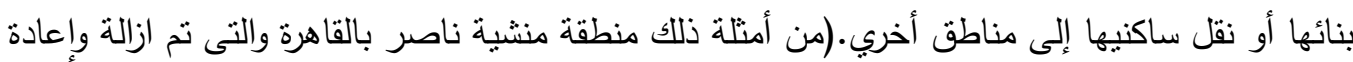
بناء العديد من أجزائها على أسس تخطيطية وإنشائية سليمة) وبالنسبة لمدينة أسيوط فأجزة الحكم المحلي للمدينـة هى أجدر الجهات لإدارة المناطق غير الرسمية بالمدينة، وذلك بحسب حالة كل منطقة غير رسمية على حدة، بشرط التتسيق مع ممنلى قاطنى تلك المناطق والمنظمات غير الحكومية الخدمية وجمعيات العمل الاجتماعي مع مجلس المدينة لإدارة تلك

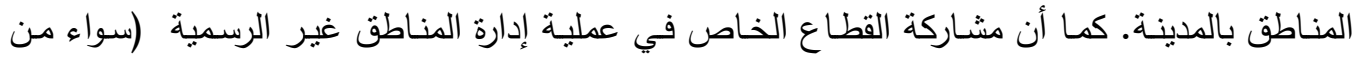

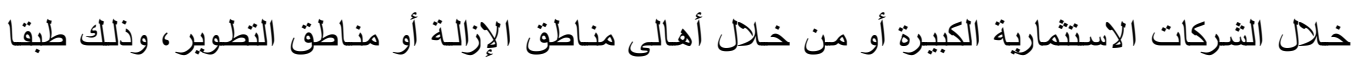

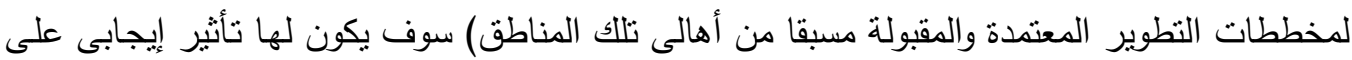

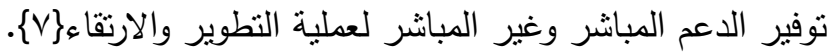

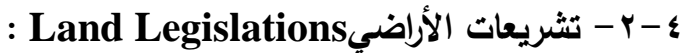

تثريعات الأراضي هي القوانين المنظمة بكل ما يختص بالأراضي"، والتىى ينت وضعها بناءاً على الروئية

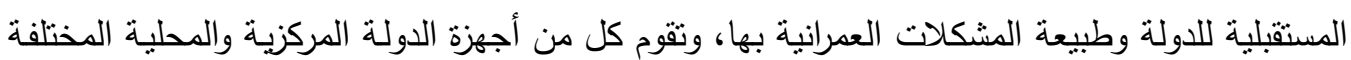

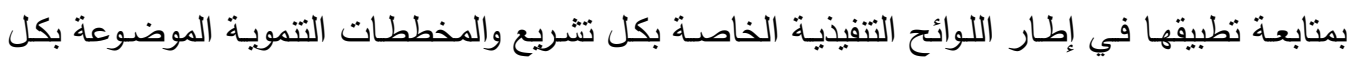

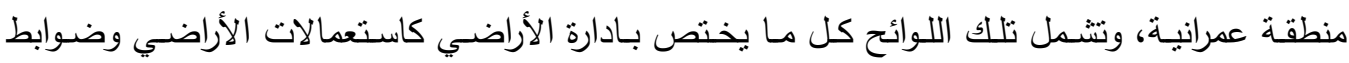
تخطيطها أو إعادة تخطيطها وأسس تقسيم المناطق الجديدة وتزويدها بالخدمات والمرافق المطلوبة ودور التهل كل الأطراف المعنية في أي مشروع تتموي وكيفية إعداد المخططات العمرانية ...إلخ.

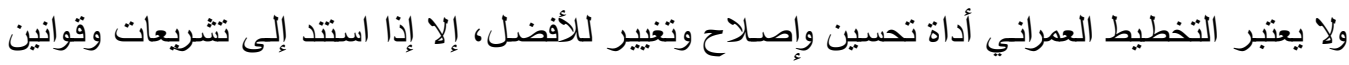

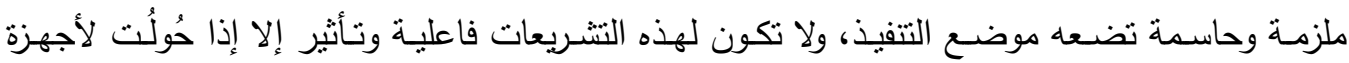

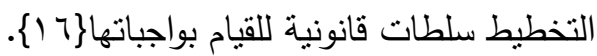

* في مصر لا توجد قو انين متخصصة في الأر اضي تحديدا، ولكنها تدخل ضمن التشريعات المنظمة للعمر ان ككل كقانون

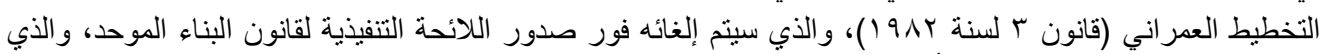

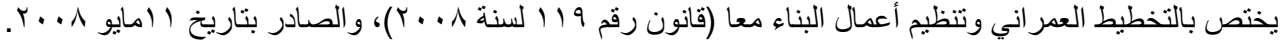


تم صدور قانون البناء الموحد والذى عالج في نصوصـه بعض الثغرات التى كانت في قانون التخطيط

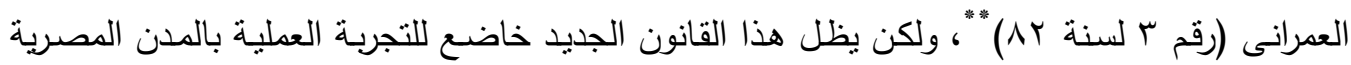
للتأكد من مدى ملائمته لظروف كل مدينة، ودراسة الحاجة إلى وجود بعض الاستثناءات أو الاشتراطات

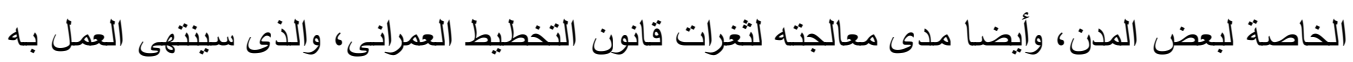

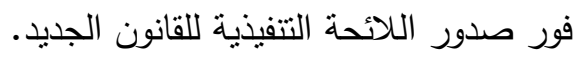

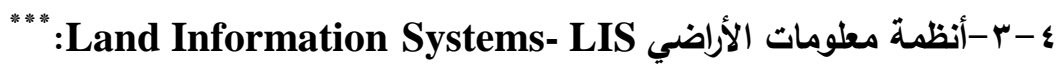

إن أبرز نطبيقات نظم المعلومات الجغرافية هى نظم معلومات الأراضي أو نظم معلومات إدارة الأراضي Land Information Management Systems

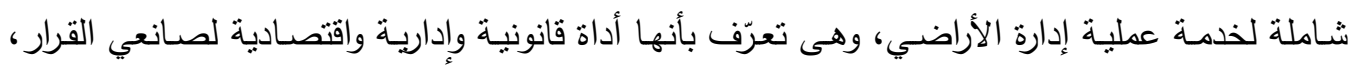

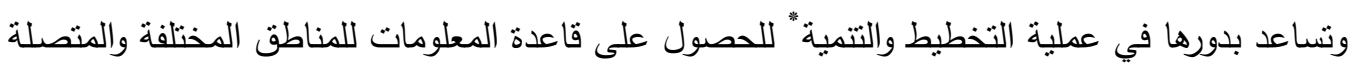
بالمعلومات المكانية للأراضي Spatially Referenced Data ، وأيضا تتفيذ عمليات تقنية وتحديث وتتغيل توزيع معلومات الأراضي بالمدن، ومنع حدوث التكرار في معلومات الأراضي. كما أن الاعتماد

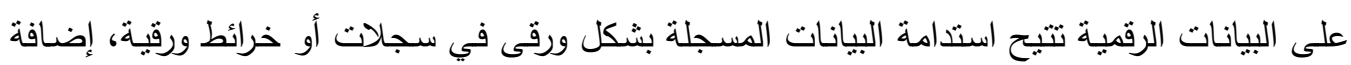
إلى سهولة تخزين واسترجاع وتعديل بيانات الأراضي، وإمكانية تخزين كميات هائلة من البيانات. إن جميع المخططات العمرانية سوف تصبح عبارة عن مجرد مخططات على ورق غير قابلة للتنفيذ

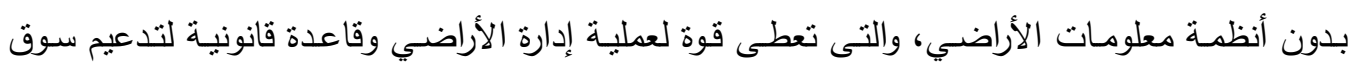

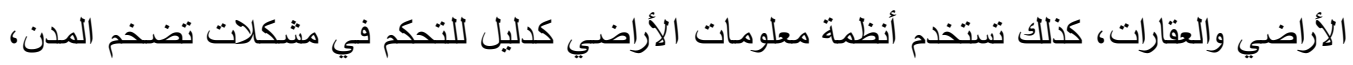

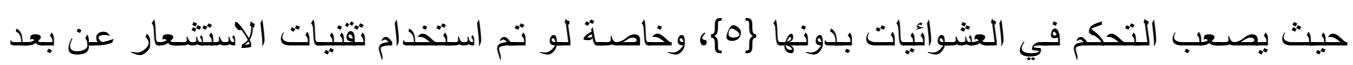

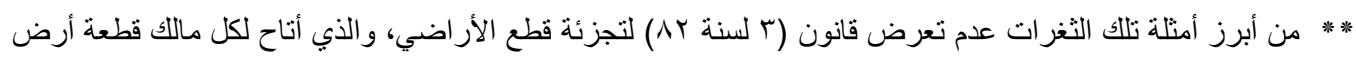

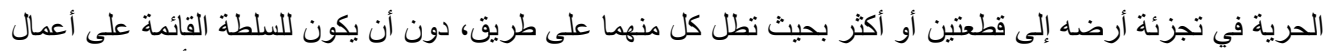

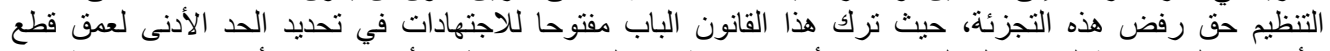

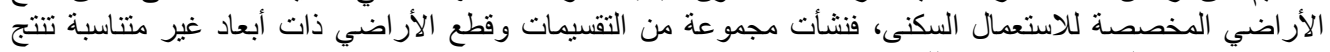

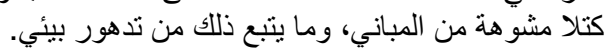

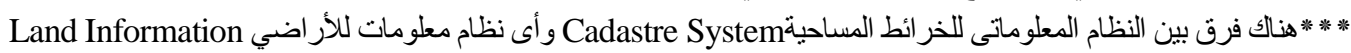

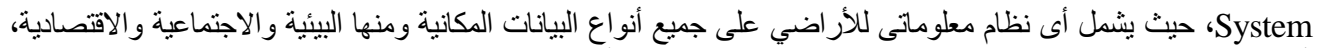

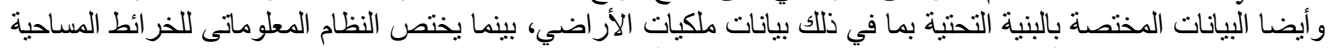

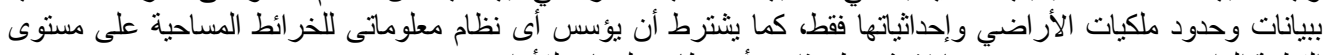

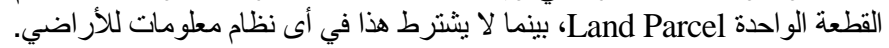

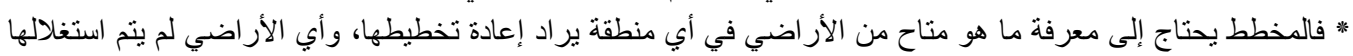

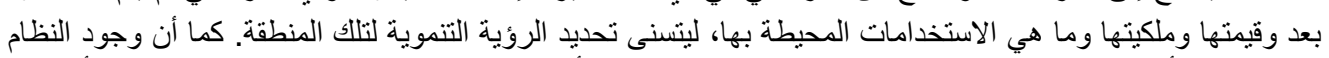

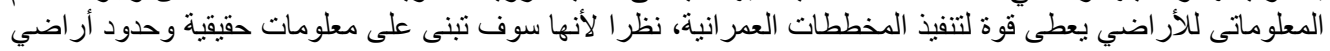

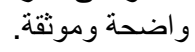


Remote Sensing التعرف على تفاصيل الحيازات والعمران بصورة واضحة، وتعطي امكانية انتاج خرائط رقمية ذات دقة بانة

عالية $\{9$ \{.

وأتاحت بعض الدول المتقدمة في هذا المجال نظم معلومات الأراضي الخاصة بها كذدمة على شبكة

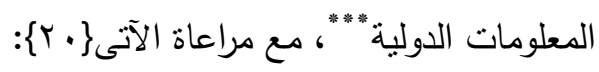

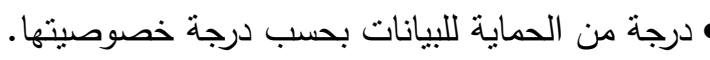
•وجود مرجعية مكانية لكل الخرائط الرقمية، أى توضيح مواقع احداثيات على الكرة الأرضية بنظام

$$
\text { إحداثى معروف. }
$$

• التدقيق ومراجعة أى بيانات قبل ادخالها لنظام المعلومات.

• أن تكون إمكانية الاستفادة من النظام من أطراف حكومية وغير التهات حكومية.

• المتابعة والتحديث المستمر لضمان حداثة كل بيانات النظام.

• سهولة استعراض وفهم العناصر المختلفة لنظام معلومات الأراضي.

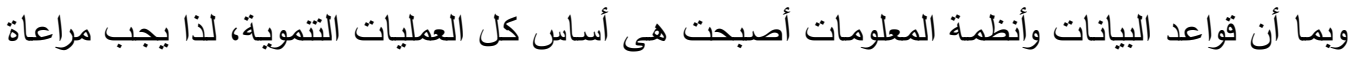

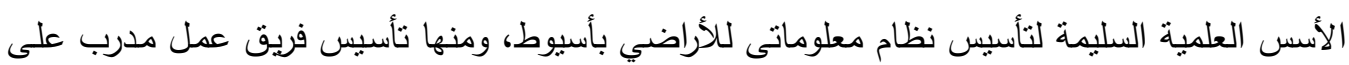

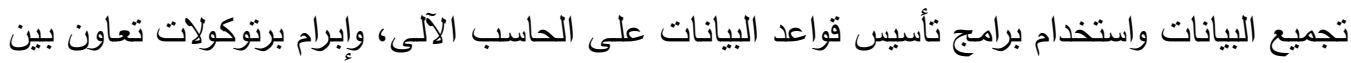

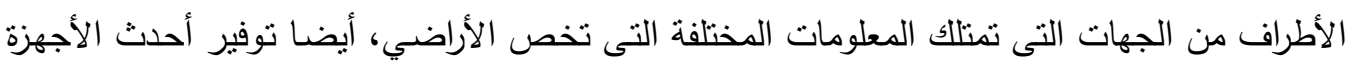

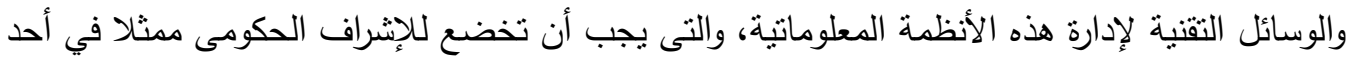

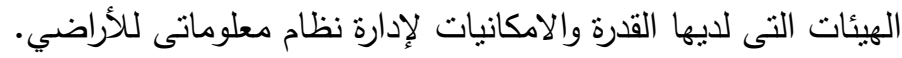

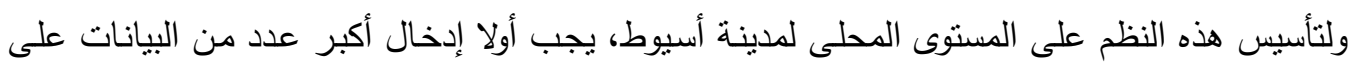

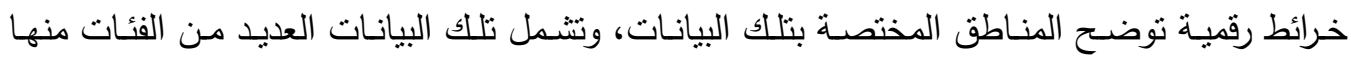
استعمالات الأراضي ومواصفات المنشآت القائمة على تلك الأراضي، ونوعية الحئه الحيازات وأسماء وبيانات

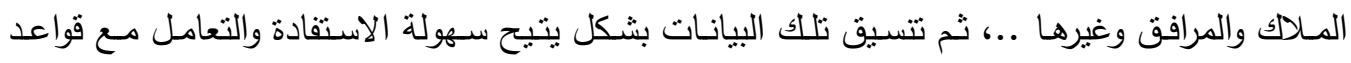
البيانات لخدمة الأغراض التتموية المختلفة.

*** الاستشعار عن بعد هو علم استخراج بيانات عن جسم محدد بدون الاتصال المباشر بهذا الجسم، وذلك عن طريق

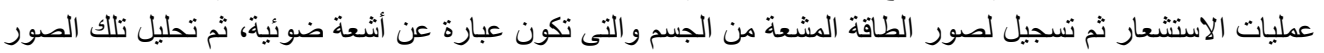

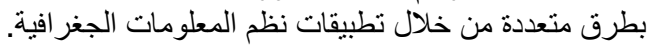

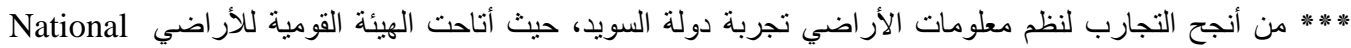

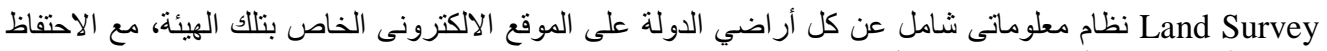
ببعض البيانات ذات الخصوصية بوسائل حماية متتو عة. 
צ - ـ - أنظمة تسجيل الأراضي Land Registration Systems: هي أنظمة نوثيق الأراضي لإثبات ملكية مالكيها في الجهات الحكومية الرختصة، وما يترتب عليها من

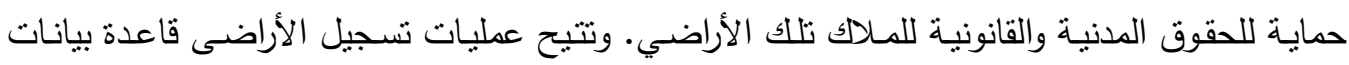

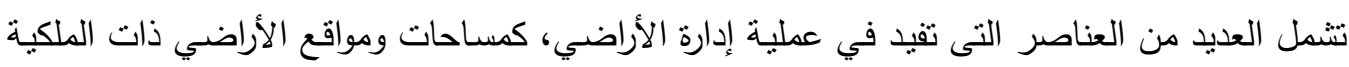

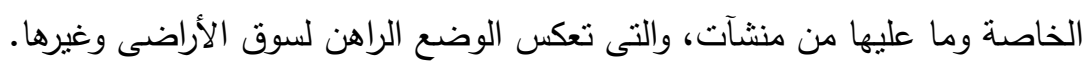

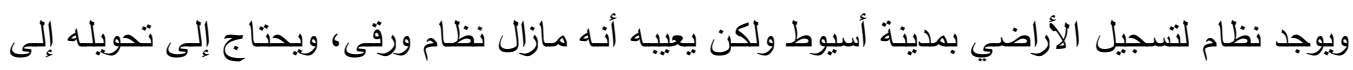

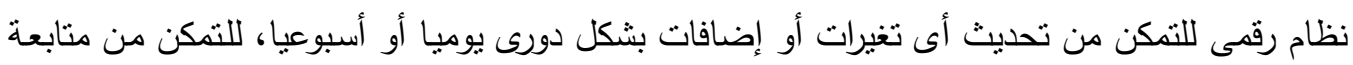
عمليات تسجيل الأراضي بالمدينة. ولتلافي مشكلات عمليات النسجيل وجعلها أكثر جدوى للمواطنين، يجب مراعاة حصول المواطنين على بلى التسهيلات المالية بعد إتمام عملية التسجيل، وذلك في حالة المشروعات التتموية بمدينة أسيوط، أيضا

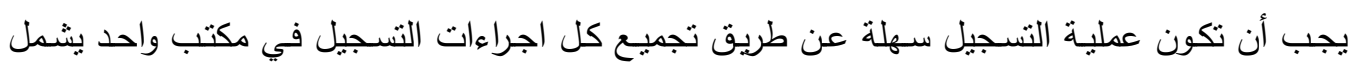
وحدة من هيئة المساحة بها نظام رقمى لتوثيق الأراضي، بالاضافة إلى الوحدة القانونية التابعة للشهري

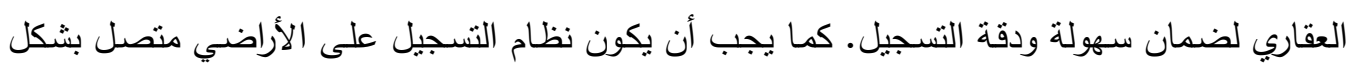

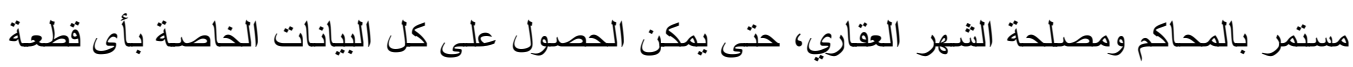

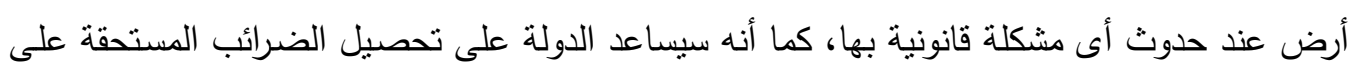

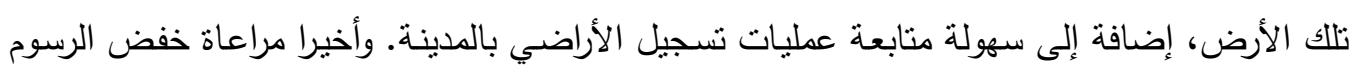

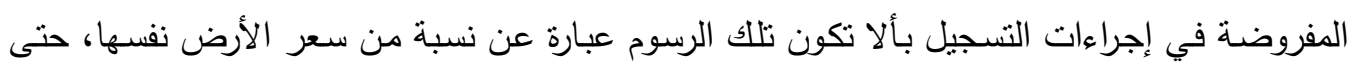

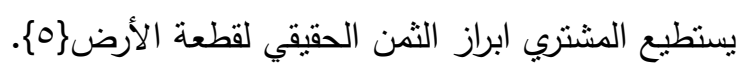

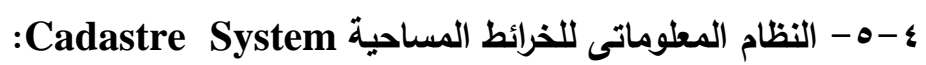

تعتبر الخرائط المساحية أدق أنواع الخرائط، حيث نتمل أنى خريطة مساحية على حدود كل ملكية من

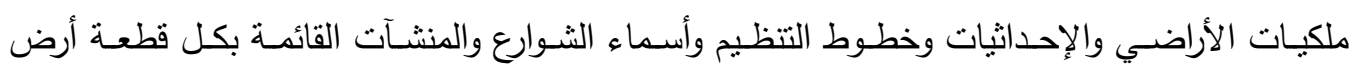
وتوصيلات المرافق وخطوط الكنتور في حالة المواقع غير المستوية، ويمكن أن تكون تلك الخرائط في

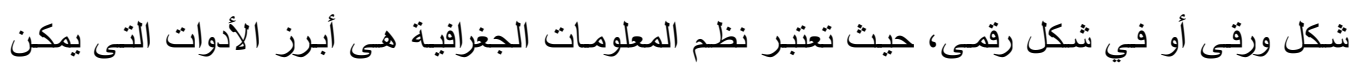

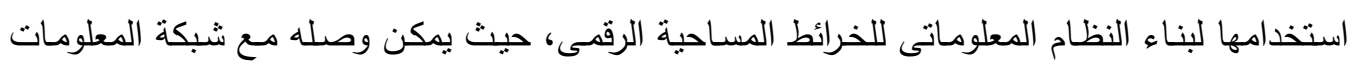
الدولي لاستخدامه كخدمة للمواطنين.

يتميز النظام الرقمى عن الورقى بسرعة ودقة وسهولة عمليتى إدخال البيانات وإخراج النتائج، كما يمكن

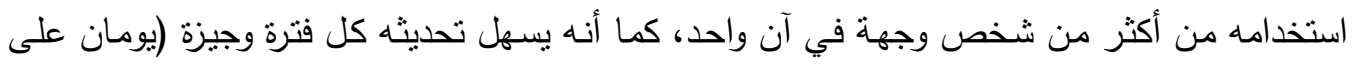

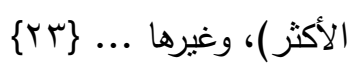


وبالنسبة لمدينة أسيوط يوجد نظام معلوماتى لخرائط مساحية للمدينة ككل في هيئة المساحة، ولكن هذا

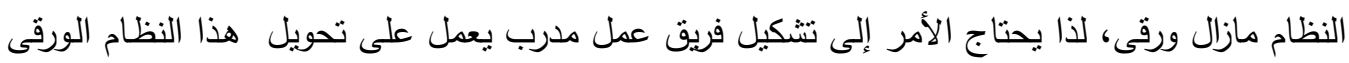

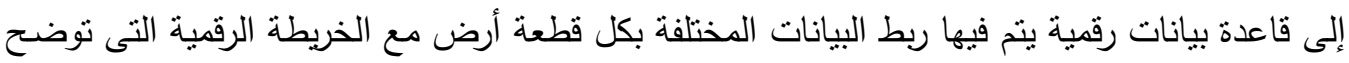

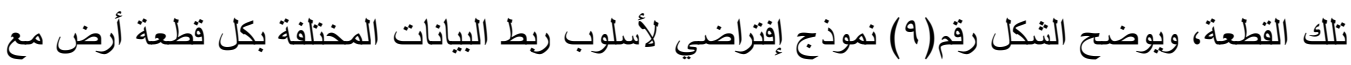

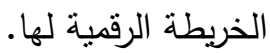

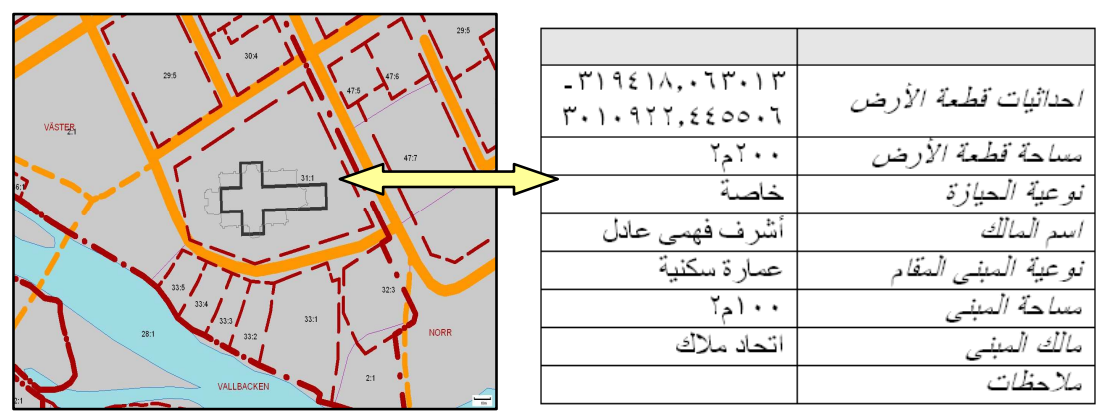

شكل رقم (9) نموذج إفتراضي لأسلوب ربط البيانات المختلفة بكل قطعة أرض مع الخريطة الرقمية لها*

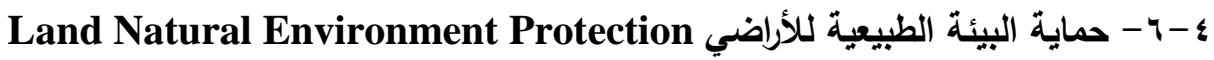
حماية البيئة الطبيعية هى الخطط المنبعة للحفاظ على البيئة الطبيعية للأراضي بأى مدينة من النلوث أو لوائه الحد منه كنقل مسبيات التلوث بعيدا، وهى لا تكون خطط مستقلة بذاتها بل تدخل في إطار المنظومة التخطيطية المتكاملة لتلك المدينة\}9 19. وبالنسبة لمدينة أسيوط يقترح البحث صياغة بروتوكول تعاون بين الجهاز الإقليمي لثئون البيئة ومجلس

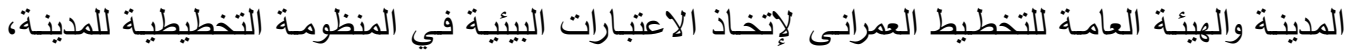

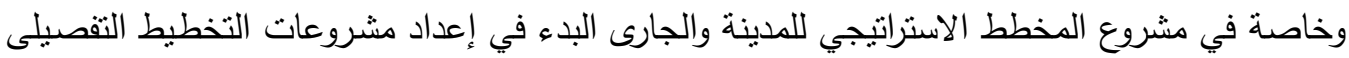
له، وفي مشروعات تقسيم الأراضي بوجه عام.

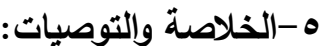

أصبحت عملية إدارة الأراضي الحضرية عملية لا غنى عنها بمدينة أسيوط لتحقيق التتمية العمرانية بشكل خاص والتتمية المستدامة بشكل عام، ليس فقط بالنسبة لمدينة أسيوط بل كذلك بالنسبة لكل المدان

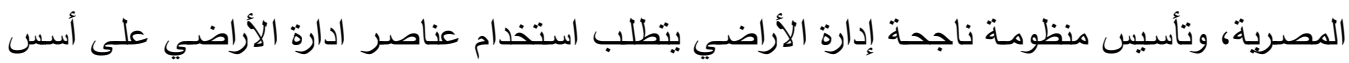

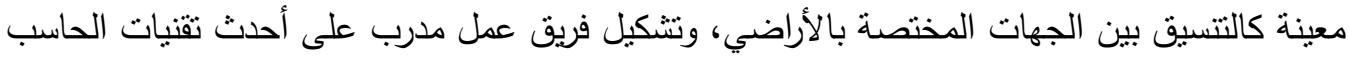


الآلى، مع الاستفادة من أحدث النظريات التخطيطية في مجال إدارة الأراضي والتي أثبت نجاحها في تجارب عملية سابقة. من خلال ما سبق يمكن الخروج بالتوصيات الآتية:

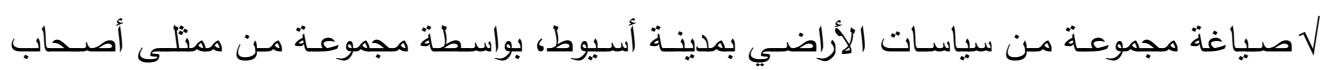

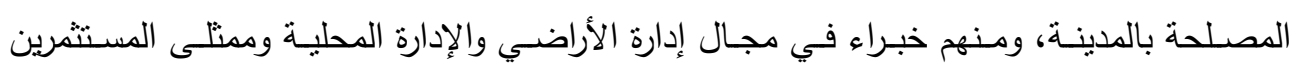

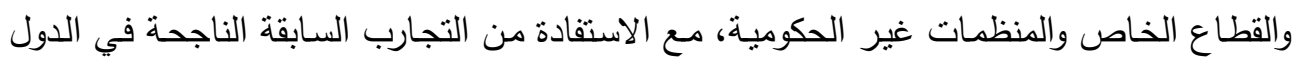
الأخرى في مجال صياغة سياسات تتمية الأراضي.

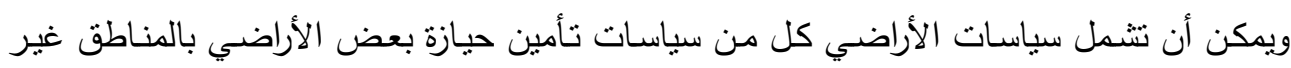

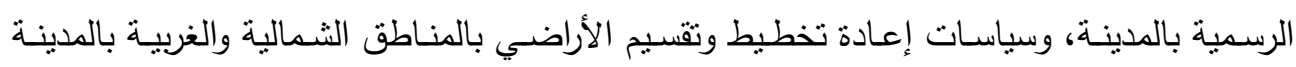

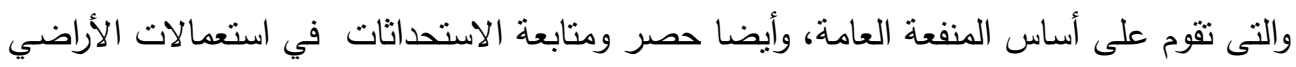

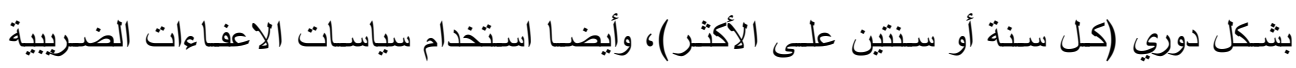

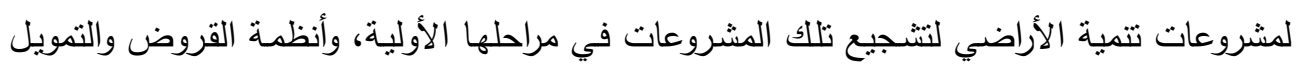
التتجيع مشروعات تتمية وتقسيم الأراضي بالمناطق المستحدثة بالمدينة، ومن أمثلتها المنطقة الواقعة الأنة

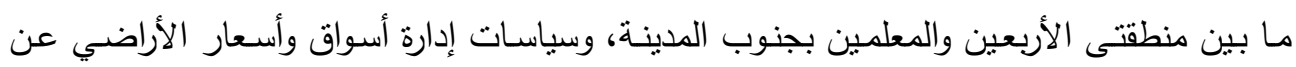

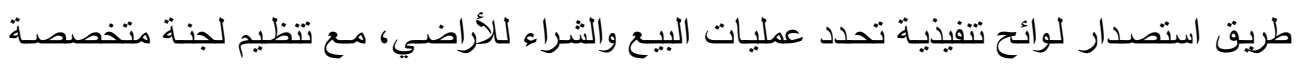

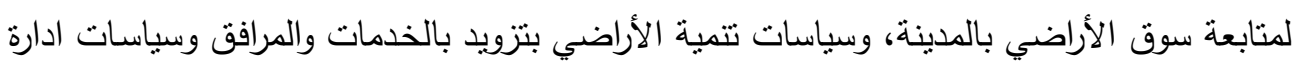
المناطق غير الرسمية تبعا لحالة كل منطقة منهم إذا كانت تحتاج إلى مجرد التطوير أو الازالة وإعادة البناء من جديد. ل يجب دراسة ومتابعة قانون البناء الموحد في الفترة الأولى لتفعيله، للوقوف على أى ثخرات يمكن أن

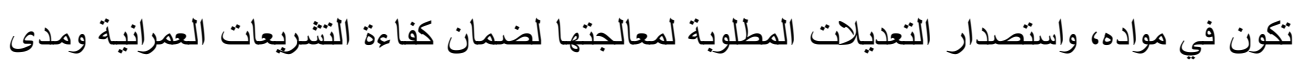
ملائمته للظروف العمرانية بمدينة أسيوط.

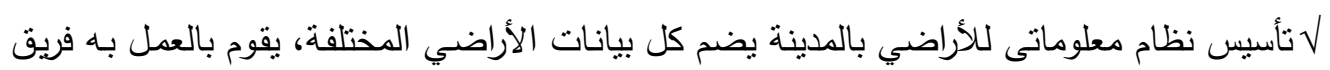
عمل متخصص وتحت اشراف الحكومة. ل تحويل نظام تسجيل الأراضي الحالى بالمدينة إلى نظام رقمى للتمكن من تحديث أى تغيرات أو إضافات بشكل دورى يوميا أو أسبوعيا، للتمكن من متابعة عمليات نسجيل الأراضي بالمدينة الهينة.

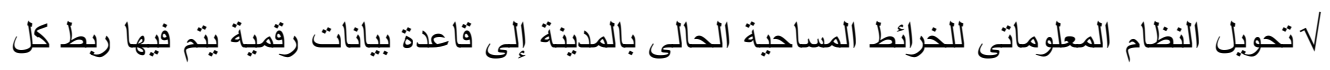
بيانات كل خريطة بالخريطة نفسها. ل لصياغة بروتوكول تعاون بين الجهاز الإقليمي لثئون البيئة والوحدة المحلية للمدينة والهيئة العامة

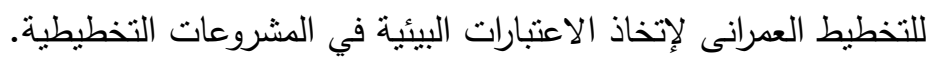




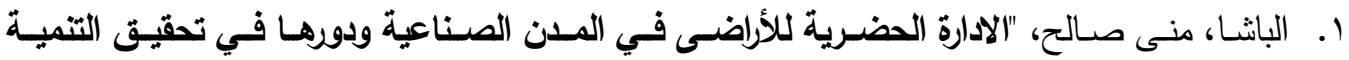

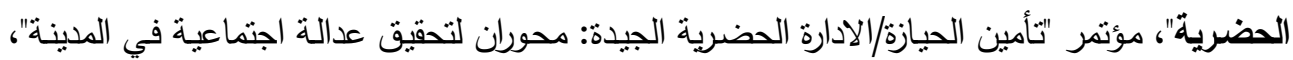

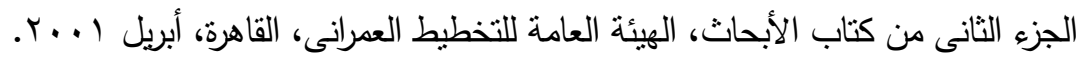

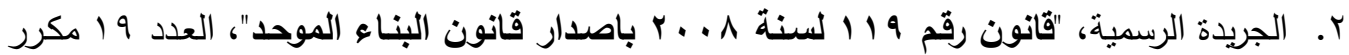

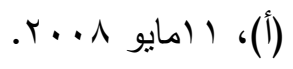

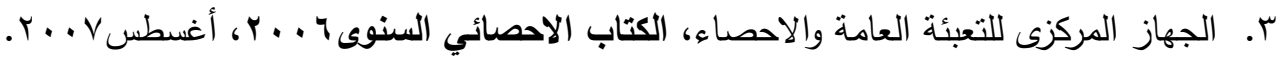

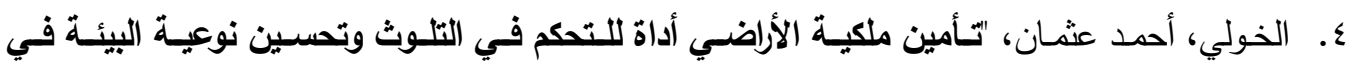
المستقرات اللارسمية "، مؤتمر "تأمين الحيازة/الادارة الحضرية الجيدة :محوران لتحقيق عدالة اجتماعية

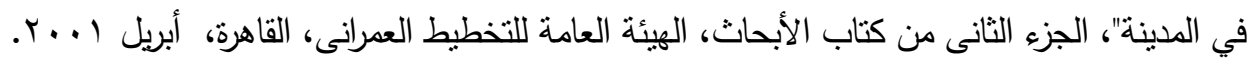

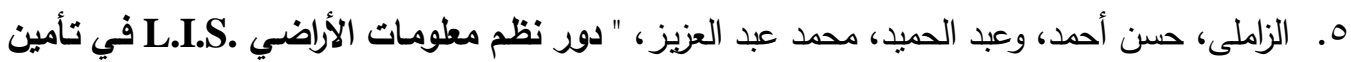

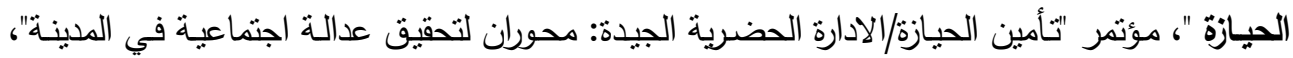

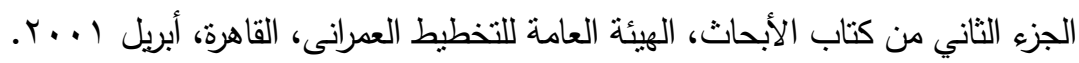

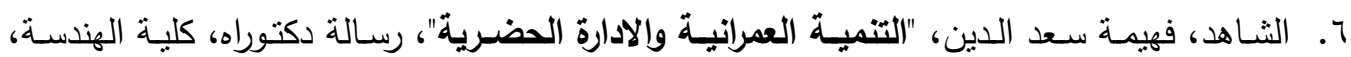

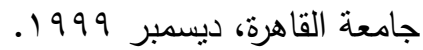
V. الثيخ، طارق عزمي، "الادارة المحلية وآليات توفير الأراضي لذوى الاخل المحدود بمصر - مدخل

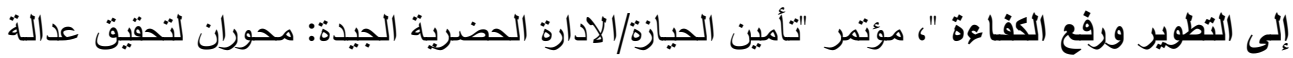

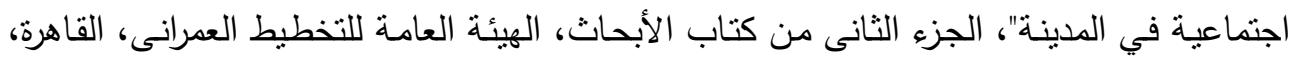

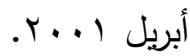

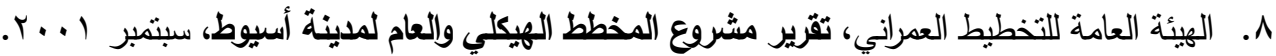
9. جادو، هثام محمود، ومحمد، ضياء الدين ابراهيم، "استخدام تقتيات الاستشعار عن بعد في تأمين الحيازة وتحليث بياناتها عمرانيا-منظومـة مقترحة لتحليد الملكيات العامـة والخاصة رقيا ويصريا"،

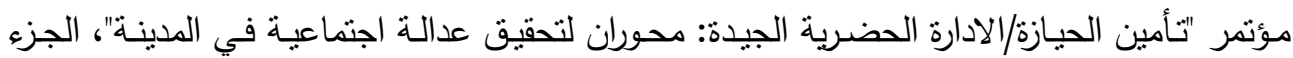

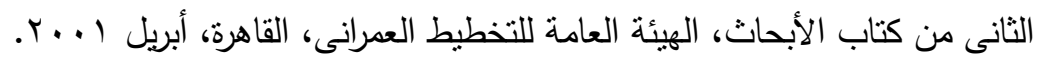

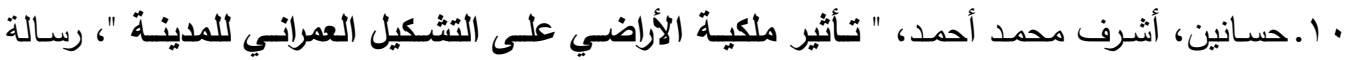

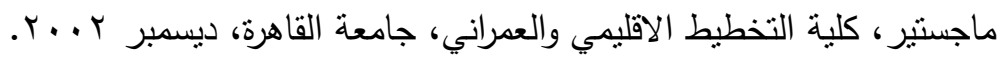

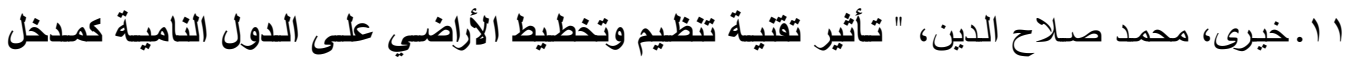
شـامل نحـو الارتقـاء والتنميـة "، رسـالة دكتوراه، قسم الهندسـة المعماريـة، كليـة الهندسـة، جامعـة 
Y ا..صـالحين، عبد الكريم، عرض لمشـروع المخطط الاسـتراتيجي لمدينـة أسيوط، محافظة أسيوط،

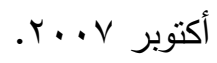

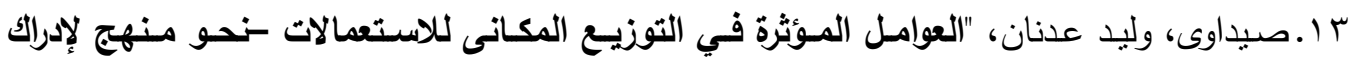

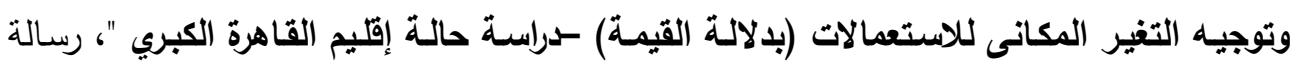

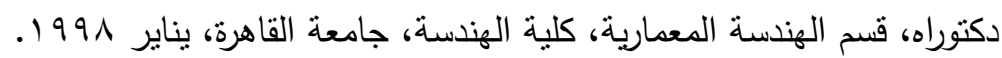

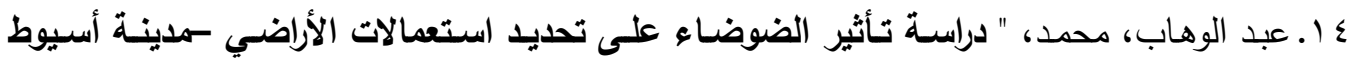

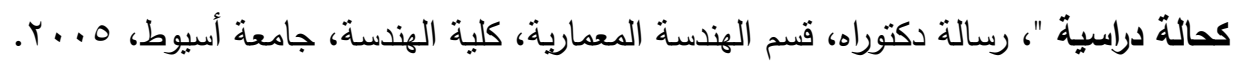

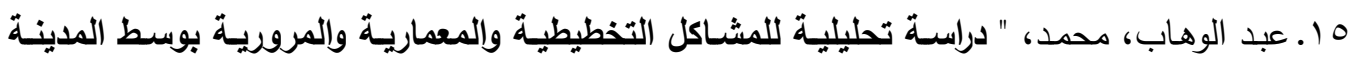
المصرية - منطقة وسط مدينة أسيوط كحالة دراسية "، رسالة ماجستير، قسم الهندسة المعمارية، كلية الهندسة، جامعة أسيوط، ـ 199 1.

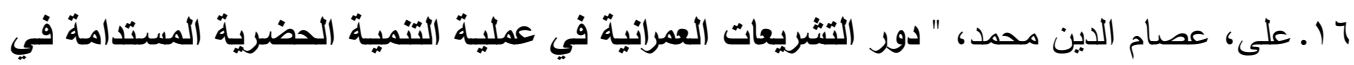

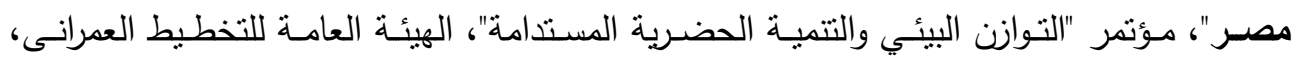

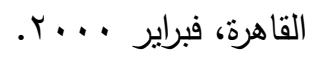

V ا.مركز استشـارات البحوث والدراسات العمرانية بالتعاون مـع الهيئة العامة للتخطيط العمرانى، كتاب

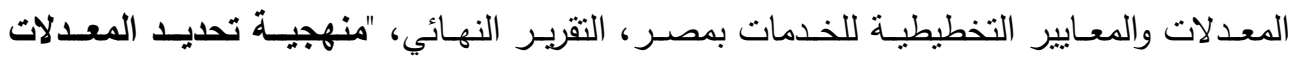

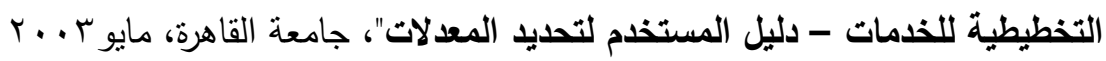

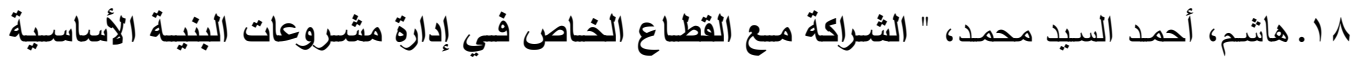

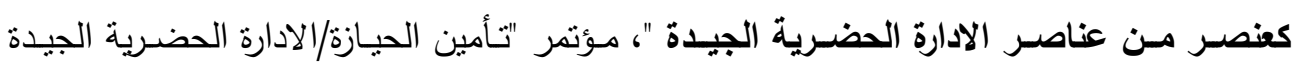

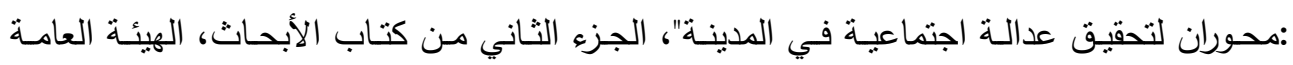

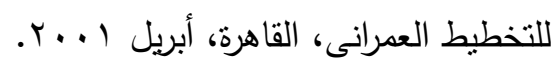

19. Deininger, Klaus, "Land Policies for Growth and Poverty Reduction", A World Bank Policy Research Report, a co publication of the World Bank and Oxford University Press, the International Bank for Reconstruction and Development /the World Bank,2003

20. Economic Commission for Europe, United Nations,"Land Administration Guidelines", Book, Geneva, April 1996

21. El-Hefnawi, Ayman Ibrahim Kamel, "Land management strategy for periurban areas -towards managing the conflict between urbanization and agricultural land protection", a $\mathrm{PhD}$ thesis, Department of Architecture ,Faculty of Engineering ,Cairo University, May 2001.

22. Finnstrom, Ake, "Land Policies for Growth and Poverty Reduction", (Lecture) ,National Land Survey Agency, Urban Land Administration Course, Sweden, April 2008.

23. Grönlund, Christina," Experiences from cadastral work in Sweden", (Lecture),Swedesurvey, Urban Land Administration Course , Kenya, Nov.2008. 
24. Österberg , Tommy," Land Tenure and Land Administration in Europe Importance for economic and social development ", Lecture,Swedesurvey, Urban Land Administration Course, Sweden, April 2008.

25. Siry, Azza Amin, "Intervention in Urban Land Use", a PhD thesis, Faculty of Regional and Urban Planning, Cairo University, 1997.

26. Swedesurvey Agency (International Agency works in the consultations of Urban Land Issues),"Land Matters", Sweden, 2008 